NBER WORKING PAPER SERIES

\title{
STOCKS, BONDS, MONEY MARKETS AND EXCHANGE RATES: MEASURING INTERNATIONAL FINANCIAL TRANSMISSION
}

\author{
Michael Ehrmann \\ Marcel Fratzscher \\ Roberto Rigobon \\ Working Paper 11166 \\ http://www.nber.org/papers/w11166 \\ NATIONAL BUREAU OF ECONOMIC RESEARCH \\ 1050 Massachusetts Avenue \\ Cambridge, MA 02138 \\ March 2005
}

We are grateful to Terhi Jokipii for excellent research assistance. We also would like to thank an anonymous referee for the ECB Working Paper series, as well as Jon Faust, Dimitrios Malliaropulos, Mark Spiegel, Cedric Tille and the participants of the ECB-IMF conference on "Global financial integration, stability and business cycles", of the New York Fed conference on "Financial globalization" and seminars at Trinity College Dublin and at Frankfurt University for comments and suggestions. This paper presents the authors' personal views and does not necessarily reflect the views of the European Central Bank. The views expressed herein are those of the author(s) and do not necessarily reflect the views of the National Bureau of Economic Research.

(C) 2005 by Giancarlo Corsetti, Philippe Martin, and Paolo Pesenti. All rights reserved. Short sections of text, not to exceed two paragraphs, may be quoted without explicit permission provided that full credit, including $($ ) notice, is given to the source. 
Stocks, Bonds, Money Markets and Exchange Rates: Measuring International Financial Transmission

Michael Ehrmann, Marcel Fratzscher, and Roberto Rigobon

NBER Working Paper No. 11166

March 2005

JEL No. E44, F3, C5

\title{
$\underline{\text { ABSTRACT }}$
}

The paper presents a framework for analyzing the degree of financial transmission between money, bond and equity markets and exchange rates within and between the United States and the euro area. We find that asset prices react strongest to other domestic asset price shocks, and that there are also substantial international spillovers, both within and across asset classes. The results underline the dominance of US markets as the main driver of global financial markets: US financial markets explain, on average, more than $25 \%$ of movements in euro area financial markets, whereas euro area markets account only for about $8 \%$ of US asset price changes. The international propagation of shocks is strengthened in times of recession, and has most likely changed in recent years: prior to EMU, the paper finds smaller international spillovers.

\author{
Michael Ehrmann \\ European Central Bank \\ Laiserstrasse 29, D - 60311 \\ Frankfurt, Germany \\ michael.ehrmann@ecb.int \\ Marcel Fratzscher \\ European Central Bank \\ Laiserstrasse 29, D - 60311 \\ Frankfurt, Germany \\ marcel.fratzscher@ecb.int \\ Roberto Rigobon \\ Sloan School of Management \\ MIT, Room E52-431 \\ 50 Memorial Drive \\ Cambridge, MA 02142-1347 \\ and NBER \\ rigobon@mit.edu
}




\section{Introduction}

Financial markets have become increasingly integrated, both domestically and internationally. The nature of this integration and the transmission channels through which shocks dissipate are, however, still not well understood. One strand of the literature focuses exclusively on spillovers across different domestic asset prices, whereas another strand concentrates on international spillovers only for individual asset prices. However, understanding the increasingly close domestic and international linkages of asset prices requires a complete and comprehensive modeling of all transmission channels that are at play. Policy makers and practitioners are well aware of the existence of these linkages, but very little is known about their strength and scope. ${ }^{1}$

The main limitation the literature has faced in measuring these propagation channels has been the endogeneity of asset prices. Clearly, macroeconomic shocks such as shocks to productivity, monetary policy, inflation expectations, risk premia, etc. have an effect on all asset prices; and therefore, estimating the impact of one innovation on the others requires identifying shocks that are unobservable at these frequencies. In this paper, we estimate the propagation of shocks by modeling each asset price with a multifactor model, and then using the heteroskedasticity that exists in the data to estimate the contemporaneous financial transmission coefficients.

In order to solve the problem of identification we need to make simplifying or identifying assumptions. The most important ones are related to the interpretation of the multifactor models. We assume that each asset price is given by a structural equation, although we understand that they are linearized versions of more complex equations describing the economy. These assumptions are well in line with VAR and monetary policy models now standard in the literature. For instance, we interpret innovations to the short rate as monetary policy shocks, to the long rate as inflationary expectations, to the stock market as productivity or supply shocks, and to the exchange rate as relative demand shocks. Under these interpretations, we can restrict the signs of several coefficients that allow us to estimate the model. In particular, we employ an empirical methodology that exploits the heteroskedasticity of asset prices as a tool for identification of financial shocks. ${ }^{2}$ This means that we can determine different regimes based on the heteroskedasticity of the underlying asset prices to pin down the direction of financial transmission process. It also implies that all

\footnotetext{
${ }^{1}$ The two possible exceptions are Andersen et. al. (2004), which studies the transmission among stock markets for each country, and then across countries for each type of asset market separately; as well as Dungey and Martin (2001) who also study the propagation of shocks across countries and markets. We discuss below in which dimensions our approach differs from these two papers.

${ }^{2}$ See Wright (1928), Sentana and Fiorentini (2001), Rigobon (2003), and Rigobon and Sack (2003a) for the theory and some applications of the methodology.
} 
of the restrictions imposed are over-identifying restrictions that can be verified empirically. We then use this approach to analyze the nature of financial integration and the transmission channels within as well as between the two largest economies in the world - the United States and the euro area. The empirical model concentrates on daily returns over a 16-year period of 1989-2004 for seven asset prices: short-term interest rates, bond yields and equity market returns in both economies, as well as the exchange rate.

The results of the paper underline the importance of international spillovers, both within asset classes as well as across financial markets. Although the strongest international transmission of shocks takes place within asset classes, we find evidence that international cross-market spillovers are significant, both statistically as well as economically. For instance, shocks to US short-term interest rates exert a substantial influence on euro area bond yields and equity markets, and in fact explain as much as $10 \%$ of overall euro area bond market movements. But the transmission of shocks also runs in the opposite direction as in particular short-term interest rates of the euro area have a significant impact on US bond and equity markets. Overall, US financial markets explain on average more than $25 \%$ of euro area financial market movements in the period 1989-2004, whereas euro area markets account for $8 \%$ of the variance of US asset prices.

A second key result of the paper is that in almost all cases the direct transmission of financial shocks within asset classes is magnified substantially, mostly by more than $50 \%$, through indirect spillovers through other asset prices. For instance, the coefficient for the direct effect of shocks to US bond yields on euro area bond markets is 0.30 , but it rises to 0.48 when allowing for indirect spillovers of these shocks via other US and euro area asset prices - where the indirect effect measures how the US shocks affect other asset prices and the exchange rate, and how those asset prices ultimately alter the euro bond rate.

These two results underline that a better understanding of financial linkages requires the modeling of international cross-market financial linkages, which so far has been mostly missing in the literature. We confirm some familiar results of the literature as, in particular, we find that financial markets are mostly driven by country-specific and market-specific factors. However, we detect a rich interaction between asset prices domestically and our methodology allows us to quantify domestic financial market transmissions much more accurately by controlling for foreign and other types of shocks. A highly revealing finding is the difference in the asset price interaction within US markets versus within euro area markets. For the US, we find that short-term interest rates react significantly to changes in domestic equity markets, whereas euro area short-term rates are not affected by stock markets. By contrast, euro area short rates and equity markets are more responsive to shocks in bond yields and exchange rates than US markets. These findings thus also identify some 
important differences in the financial transmission processes within the two economies, which may reflect differences in economic structure, in the degree of openness as well as different policy objectives. Finally, we conduct several sensitivity tests and show that the results are broadly robust, although we find some suggestive indication that the international transmission channel has intensified significantly over time, and in particular since EMU. Furthermore, we find that the international propagation of shocks is strengthened in times of recession.

The paper is organized in the following way. Section II. briefly reviews the literature on domestic and on international financial linkages and integration. The methodology based on identification through heteroskedasticity is summarized in Section III. Section IV. outlines the data and the empirical findings for domestic and international asset market spillovers between the United States and the euro area. Section V. discusses caveats and robustness results and Section VI. summarizes and concludes with some policy implications arising from the findings.

\section{Related literature}

The literature on financial linkages has evolved along two separate strands in recent years. One of these strands has been focusing on the domestic transmission of asset price shocks and its determinants. Another direction of the literature has been to analyze international linkages, whereby the focus, however, has been mostly on individual asset prices in isolation - usually equity markets or foreign exchange markets.

Linkages across domestic financial markets are increasingly well-understood. Earlier work on the spillovers across different domestic asset prices often finds a positive correlation between stock returns and bond yields, such as Shiller and Beltratti (1992) and to some extent Barsky (1989) and Campbell and Ammer (1993) for the United States, though the analysis of those studies is mostly based on low-frequency data. More recent work finds that equity prices react strongly to monetary policy shocks in the United States (Bernanke and Kuttner 2004, Ehrmann and Fratzscher 2004a) At the same time, monetary policy has been shown to respond to equity markets (Rigobon and Sack 2003a). In a simultaneous analysis of bond prices, short-term interest rates and equity markets, Rigobon and Sack (2003b) find that the causality of the transmission process may run in several directions, as for instance the correlation between US short-term interest rates and equity prices may change from positive to negative depending on which of the asset prices is dominant in particular periods.

A closely related literature focuses on explaining the price discovery process in domestic asset prices through economic fundamentals. Several papers concentrate thereby on 
the importance of announcements and news of selected macroeconomic variables. Fleming and Remolona (1997, 1999), Balduzzi, Elton and Green (2001), and Bollerslev, Cai and Song (2000) show that macroeconomic news in the US are an important driving force behind US bond markets. Fleming and Remolona (1999) find a hump-shaped effect of macroeconomic news along the yield curve in that the largest effect of such news usually occurs at intermediate maturities. For equity markets, Flannery and Protopapadakis (2002) and Boyd, Jagannathan and $\mathrm{Hu}$ (2001) also reveal a strong response of US equity markets to macroeconomic news, while the latter paper as well as David and Veronesi (2004) show that the relationship between economic fundamentals and equity returns may in some cases be dependent on economic conditions or the type of news.

There have also been various attempts to analyze international spillovers, though the focus in this literature has so far concentrated only on individual asset prices in isolation, mostly on equity markets. For instance, the empirical work by Hamao, Masulis and $\mathrm{Ng}$ (1990), King, Sentana and Wadhwani (1994) and Lin, Engle and Ito (1994), based on reduced-form GARCH models, detects some spillovers from the US to the Japanese and UK equity markets, both for returns and in particular for conditional volatility. Also Becker, Finnerty and Friedman (1995) find spillovers between the US and UK stock markets and show that this is in part due to US news and information, although more recent work by Connolly and Wang (2003) argues that such macroeconomic news can explain only a small share of the equity market spillovers between mature economies. For foreign exchange markets, the seminal papers by Engle, Ito and Lin (1990) and Andersen and Bollerslev (1998) find strong spillovers in foreign exchange markets, both in conditional first and second moments. Finally, a related paper studying contagion across different countries and financial markets is Dungey and Martin (2001). They study mainly the transmission of volatility between short interest rate markets and stock markets across countries.

A related literature focuses on the effects of macroeconomic announcements on various asset prices. Andersen, Bollerslev, Diebold and Vega (2003) and Ehrmann and Fratzscher (2004c) show that in particular US macroeconomic news have a significant effect on the US dollar - euro exchange rate. For bond markets Goldberg and Leonard (2003) and Ehrmann and Fratzscher (2004b) find that not only macroeconomic news are an important driving force behind changes in bond yields, but that there are significant international bond market linkages between the United States and the euro area. The results of Ehrmann and Fratzscher (2004b) indicate that spillovers are stronger from the US to the euro area market, but that spillovers in the opposite direction are present since the introduction of the euro in 1999. Finally, Andersen, Bollerslev, Diebold and Vega (2004), Fair (2003) and Faust, Rogers, Wang and Wright (2003) look at the effect of macro announcements on high-frequency asset 
returns across several asset prices, such as exchange rates and the yield curve, confirming the importance of news and in some cases finding a significant response of risk premia or an overshooting of exchange rates in the short run.

Another strand on international financial co-movements attempts to explain the evolution of financial spillovers through real and financial linkages of the underlying economies. Heston and Rouwenhorst (1994), Griffin and Karolyi (1998) and Brooks and del Negro (2002) argue that mainly country-specific shocks, and to a lesser extent industryspecific and global shocks, can explain international equity returns. In addition, several papers emphasize the importance of linkages through trade and capital flows for explaining financial market spillovers. One direction of the literature has been to focus on contagion in international markets, marked by the seminal work by Bae, Karolyi and Stulz (2003) and Forbes and Rigobon (2002). Hartmann, Straetmans and de Vries (2003) show that exchange rate linkages strengthen during financial crises for a broad set of emerging markets. Eichengreen and Rose (1999) and Glick and Rose (1999) find that the degree of bilateral trade rather than country-specific fundamentals alone play an important role for understanding financial co-movements during crisis episodes. Focusing on mature economies, Forbes and Chinn (2003) find that the country-specific factors have become somewhat less important and bilateral trade and financial linkages significantly are nowadays more important factors for explaining international spillovers across equity and bond markets.

A key characteristic of this literature on financial transmission is that it has evolved along distinct paths, one focusing exclusively on domestic cross-market linkages and others on the international transmission within individual asset markets. Few systematic attempts have been made to link these strands in order to gain a better understanding of the underlying nature of the transmission channels of financial shocks. The objective of this paper is to provide a framework for analyzing the interaction of the domestic and international transmission of financial market shocks.

\section{Measuring Domestic and International Financial Integration}

\section{III.1 The "structural-form" and the "reduced-form" models}

Our behavioral model implies the following structural form:

$$
A y_{t}=\vartheta+\Pi(L) y_{t-1}+\Psi(L) z_{t}+\mu_{t}
$$


where $\mathrm{y}_{\mathrm{t}}$ is a vector $y_{t} \equiv\left(r_{t}^{U S}, b_{t}^{U S}, s_{t}^{U S}, r_{t}^{E A}, b_{t}^{E A}, s_{t}^{E A}, e_{t}\right)$ of the seven endogenous asset prices, namely the change in short- term interest rates $\left(\mathrm{r}_{\mathrm{t}}\right)$, the change in long-term bond yields $\left(b_{t}\right)$ and stock market returns $\left(s_{t}\right)$, for each of the two economies, and the change in the exchange rate $\left(e_{t}\right) . \Pi(L)$ captures the lagged effects of the endogenous variables $y_{t}$ and $\Psi(L)$ the lagged and contemporaneous effects of a set of exogenous variables and common shocks $\mathrm{z}_{\mathrm{t}}$. We will return below to explaining in more detail how $\mathrm{z}_{\mathrm{t}}$ is constructed and what it includes. The $7 \times 7$ matrix $A$ is of main interest to us as its off-diagonal elements capture the contemporaneous interactions across asset markets. Finally, $\mu_{\mathrm{t}}$ is the vector of structural-form innovations $\mu_{\mathrm{i}, \mathrm{t}}$ of the behavioral model, which reflects shocks to the underlying asset prices. For $\mu_{\mathrm{i}, \mathrm{t}}$ to truly represent structural-form innovations, it needs to hold that they have zero mean, and are orthogonal to one another, both contemporaneously and across time:

$$
\begin{array}{ll}
E_{t}\left(\mu_{i, t} \mu_{j, t}\right)=0 & \forall i \neq j \\
E_{t}\left(\mu_{i, t} \mu_{j, t^{\prime}}\right)=0 & \forall i \neq j, t \neq t^{\prime}
\end{array}
$$

The starting point for identification is to estimate the reduced-form - or factor - model of equation (1) via OLS:

$$
\begin{aligned}
& y_{t}=A^{-1} \vartheta+A^{-1} \Pi(L) y_{t-1}+A^{-1} \Psi(L) z_{t}+\varepsilon_{t} \\
& y_{t}=C_{0}+B_{0}(L) y_{t-1}+B_{1}(L) z_{t}+\varepsilon_{t}
\end{aligned}
$$

with the reduced-form residuals $\varepsilon_{\mathrm{t}}$ as

$$
\varepsilon_{t}=\left\{\varepsilon_{r, t}^{U S}, \varepsilon_{b, t}^{U S}, \varepsilon_{s, t}^{U S}, \varepsilon_{r, t}^{E A}, \varepsilon_{b, t}^{E A}, \varepsilon_{s, t}^{E A}, \varepsilon_{e, t}\right\}^{\prime}=A^{-1}\left\{\mu_{r, t}^{U S}, \mu_{b, t}^{U S}, \mu_{s, t}^{U S}, \mu_{r, t}^{E A}, \mu_{b, t}^{E A}, \mu_{s, t}^{E A}, \mu_{e, t}\right\}^{\prime}
$$

The next question, then, is to determine if the structural coefficients can be identified from the reduced-form estimates. The coefficients that can be estimated from the data are $C_{0}, B_{0}, B_{1}$ and the covariance matrix of the reduced-form residuals. If $A$ was known, then $C_{0}, B_{0}, B_{1}$ are sufficient to recover the structural coefficients $\vartheta, \Pi, \Psi$. The covariance matrix of the reduced-form residuals has 28 elements (the diagonal 7, and the covariances). This covariance matrix has to be used to explain the covariance matrix of the structural-form residuals (which only has 7 unknowns given our assumption about zero correlation across structural shocks), and the matrix $A$ (which has ones on the diagonal and therefore has 42 coefficients that need estimating). This is the standard problem of identification: We have 28 equations (from the reduced-form residuals) and $49(7+42)$ unknowns. Hence, there are more unknowns than 
equations, which means that a continuum of solutions exists and that some method of identification is required.

One standard econometric technique that has frequently been employed to study problems of this kind resorts to structural vector autoregression (SVARs), which goes back to the work by Sims (1980). The idea is to impose restrictions on some parameters of the empirical model, which are ideally derived from economic theory, yet remain untestable, as they are required for identification. A frequently used methodology consists in a Cholesky decomposition, which maintains that the matrix A is triangular. In this fashion, the model is exactly identified, as 21 zero-restrictions are imposed. As an alternative, sign restrictions on the parameters of A have been used, which cannot uniquely pin down the parameters, yet are able to identify the space in which the parameters can lie.

We will show in section IV. that both approaches are inappropriate for our purposes, as the standard Cholesky decomposition fails to achieve the proper identification, and sign restrictions lead to an extremely large admissible parameter space. Therefore, we will employ an alternative approach to identification, which we discuss in the next sub-section.

\section{III.2 Identification through heteroskedasticity}

In this paper, we use an alternative methodology for identification, known as identification through heteroskedasticity $(\mathrm{IH})$. This methodology uses the fact that financial variables are generally found to be heteroskedastic. The form of such heteroskedasticity is of no particular interest to us. It could be described as a GARCH model (Rigobon and Sack 2003b), or a regime switching model. As is shown in Rigobon (2003), the estimates of the contemporaneous coefficients are consistent, regardless of how the heteroskedasticity is modeled. Therefore, for simplicity, we assume that there are $\mathrm{N}$ regimes.

Under this assumption, we obtain one additional covariance matrix in the structural model for each heteroskedastic regime $s$ (which adds 7 unknowns), but in each regime we can estimate a new reduced-form covariance matrix (which provides 28 new equations). Accordingly, there are enough equations to solve the system of equations if

$$
S * 28 \geq S * 7+42
$$

which is satisfied for $S \geq 2$ heteroskedasticity regimes.

Note that this methodology of identification is based on two crucial assumptions. First, the structural shocks are uncorrelated. This means that each additional heteroskedastic regime adds more equations than unknowns. Second, we assume that the matrix $A$ is stable across heteroskedastic regimes. Although the system is identified by the number of regimes, 
this is only true up to a rotation of the matrix A. We therefore need to impose some additional restrictions to ensure that we pick the "correct" rotation, which represents the underlying economic relationships. However, as these are overidentifying restrictions, it is possible to test whether they are binding or not.

To illustrate this with an example let's study the standard supply and demand equation set up:

$$
\begin{aligned}
& p_{t}=\alpha q_{t}+\varepsilon_{t} \\
& q_{t}=\beta p_{t}+\eta_{t}
\end{aligned}
$$

where the first is the demand equation and the second one is the supply equation. This system of equations has the exact same reduced-form variance-covariance matrix as the following, alternative system:

$$
\begin{aligned}
& p_{t}=-\frac{1}{\beta} q_{t}-\frac{1}{\beta} \eta_{t} \\
& q_{t}=-\frac{1}{\alpha} p_{t}-\frac{1}{\alpha} \varepsilon_{t}
\end{aligned}
$$

In fact, both have the exact same reduced-form

$$
\begin{aligned}
& p_{t}=\frac{1}{1-\alpha \beta}\left(\varepsilon_{t}+\alpha \eta_{t}\right) \\
& q_{t}=\frac{1}{1-\alpha \beta}\left(\beta \varepsilon_{t}+\eta_{t}\right)
\end{aligned}
$$

But, as should be obvious, the first and second systems of equations are the same except that in the demand equation we solve once for quantities instead of prices, and the opposite for the supply equation. Because both systems produce the exact same reduced-form, the question is which of the two solutions we should pick. Here is where the sign restrictions come into play. If we impose that the demand equation is downward sloping and the supply equation is upward sloping, then we know that $\alpha$ is negative and $\beta$ is positive. Note that this can only occur in the first system of equations, given that the second one implies exactly the opposite signs. The signs only help in the identification because they allow us to determine which of the solutions is the one that is economically meaningful, and it should be stressed again that the validity of the over-identifying restrictions can be tested explicitly.

\section{III.3 Identification restrictions}

In order to impose sensible restrictions, we start by discussing the meaning of each of the equations in the system. For the purpose of illustration, we can write the A matrix of the structural-form model as follows 


$\begin{aligned} & r^{U S} \\ & b^{U S} \\ & s^{U S} \\ & r^{E A} \\ & b^{E A} \\ & s^{E A} \\ & e\end{aligned} \quad A=\left(\begin{array}{ccccccc}1 & \alpha_{12} & \alpha_{13} & \beta_{14} & \beta_{15} & \beta_{16} & \gamma_{17} \\ \alpha_{21} & 1 & \alpha_{23} & \beta_{24} & \beta_{25} & \beta_{26} & \gamma_{27} \\ \alpha_{31} & \alpha_{32} & 1 & \beta_{34} & \beta_{35} & \beta_{36} & \gamma_{37} \\ \beta_{41} & \beta_{42} & \beta_{43} & 1 & \alpha_{45} & \alpha_{46} & \gamma_{47} \\ \beta_{51} & \beta_{52} & \beta_{53} & \alpha_{54} & 1 & \alpha_{56} & \gamma_{57} \\ \beta_{61} & \beta_{62} & \beta_{63} & \alpha_{64} & \alpha_{65} & 1 & \gamma_{67} \\ & & & & & & \\ \gamma_{71} & \gamma_{72} & \gamma_{73} & \gamma_{74} & \gamma_{75} & \gamma_{76} & 1\end{array}\right)$

so that the $\alpha$ parameters indicate the spillovers across domestic asset prices within the United States and within the Euro Area, the $\beta$ parameters the international spillovers, and $\gamma$ the spillovers from and to the USD-EUR exchange rate.

Turning to the interpretation of the equations, the equations for the short-term interest rate can essentially be interpreted as a high-frequency monetary policy reaction function. Of course, monetary policy authorities do not adjust policy rates at a daily frequency, but the reaction of short-term rates reflects to a significant extent the market's expectations about the course of monetary policy in the short- to medium term. The equation of long-term interest rates may be understood as reflecting inflation expectations over the medium- to long-run. Hence a fall at the long end of the yield curve may at least in part indicate that markets anticipate lower inflation rates, conditional on the current short rate.

The stock market equation may be interpreted as a proxy of domestic demand in that a positive demand shock at home raises domestic equity prices. Alternatively, changes in equity prices may also be explained by supply shocks, such as productivity changes. Finally, the exchange rate movements may be understood as reflecting changes in the relative demand across the two economies (see Pavlova and Rigobon 2004). Of course, these interpretations are in no way clear-cut, and may not exclude alternative interpretations and explanations. When discussing the empirical results, we will go in more detail about the interpretation of each of the equations and possible caveats.

We impose a first set of identification restrictions on domestic asset price spillovers, as we can use existing priors about their signs from the literature. Most restrictions are actually imposed on monetary policy, as this is probably the best understood subsystem in our model. Note that, since the matrix $A$ pre-multiplies the vector of endogenous variables on the left- 
hand side of equation (1), the sign of the restriction is opposite to the expected reaction of asset prices. The assumptions are the following:

1. We would expect that an inflationary shock should trigger market expectations of a monetary tightening and thus a rise in short-term rates (due to the opposite sign we need to impose on $A$, this implies $\alpha_{12}, \alpha_{45}<0$ ).

2. Similarly, one would expect that a positive shock to stock markets raises short-term interest rates $\left(\alpha_{13}, \alpha_{46}<0\right)$ if monetary policy were expected to respond to equity price shocks.

3. As to the effects of monetary policy, an increase in short-term interest rates raises the discount value and lowers the demand for goods and services and hence should lead to a decline in equity prices $\left(\alpha_{31}, \alpha_{64}>0\right)$.

4. Moreover, also a rise in long-term interest rates should lower equity prices $\left(\alpha_{32}, \alpha_{65}>\right.$ $0)$. Since we believe that these lines of reasoning should apply both to the direct effects of shocks on asset prices (as measured by the matrix A) as well as the overall effects, including indirect spillovers (as measured by $\mathrm{A}^{-1}$ ), we impose the equivalent set of restrictions on $\mathrm{A}^{-1}$.

Turning to the international linkages, our theoretical priors for some of the spillovers are fairly clear-cut but less so for others.

5. A positive shock to domestic equity prices should induce a positive spillover and lead to a rise in foreign equity markets as firms and demand are linked internationally ( $\beta_{36}$, $\beta_{63}<0$ ). Most of the literature on contagion has shown that these spillovers are indeed positive. For a theoretical justification see Zapatero (1995), Cass and Pavlova (2004) and Pavlova and Rigobon (2004).

6. Similarly, domestic and foreign money markets and bond markets should exhibit positive spillovers $\left(\beta_{14}, \beta_{41}<0 ; \beta_{25}, \beta_{52}<0\right)$. This has indeed been found to hold empirically between the United States and the euro area in Ehrmann and Fratzscher (2004b), based on a reduced-form GARCH-type of model. However, various channels may explain this positive relationship. On the one hand, the openness of financial markets and arbitrage may mean that interest rate shocks are transmitted across economies. On the other hand, a close real integration of two economies may imply that a monetary policy shock or an inflationary shock in one economy may lead investors to expect similar developments in the other, thus inducing a significant transmission of shocks in money and bond markets. Whatever the precise direct channel of transmission, we can test whether these linkages are empirically relevant. 
7. We normalize all variables and therefore we impose the restrictions that the international spillovers within markets - within equity markets, within money markets and bond markets - are positive and less than one. This assumption boils down to assume that a domestic shock should not have an amplified and more than proportional effect on foreign markets $\left(-1<\beta_{14}, \beta_{41}, \beta_{25}, \beta_{52}, \beta_{36}, \beta_{63}<0\right)$. This assumption is reasonable for developed economies, whereas it may be incorrect for emerging markets. Moreover, we add a restriction that reflects our prior that the overall spillovers from the US money and equity markets to the equivalent euro area markets should be larger than those emanating from the euro area.

These restrictions have been imposed on the structural coefficients. In fact, we find in the empirical results that these restrictions are not binding, but they help us further in the process of identification. The next issue relates to the international cross-market spillovers. Recall that the parameters in the structural-form or behavioral model should be interpreted as indicating only the direct linkages between markets, whereas the parameters of the reducedform model capture both direct as well as indirect linkages across asset prices. By indirect linkages we mean spillovers of shocks that occur via other asset prices. For international cross-market spillovers it is hard to see how, for instance, a rise in short-term interest rates in the Unites States should have a direct impact on euro area equity prices $\left(\beta_{61}\right)$. Of course, a rise in US interest rates is likely to affect also euro area equity prices, but this effect should be an indirect one in the sense that it is transmitted through other asset prices such as euro area interest rates. In this case, a rise in US interest rates induces an increase in euro area rates, which then in turn raises the discount factor for and causes a drop in euro area equity prices.

8. Hence, in addition to the overall sign, we also impose zero restrictions on all international cross-market spillovers in the structural-form model. This assumes that the cross-market cross-country spillover are zero, but remember that we still allow for indirect spillovers in the reduced-form model indicated by the matrix $\mathrm{A}^{-1}$. Moreover, in the sensitivity analysis we relax these restrictions one by one to test for the robustness of the estimates.

9. Finally, we restrict some $\gamma$ parameters for the spillovers from and to the USD-EUR exchange rate. We presume that an increase in long rates in the US leads to a portfolio shift into US assets, leading to an appreciation of the dollar and vice versa $\left(\gamma_{72}>0, \gamma_{75}<0\right)$.

10. We apply the same reasoning to shocks to the respective stock markets $\left(\gamma_{73}>0, \gamma_{76}<\right.$ 0 ) in the structural-form model, although we allow for unrestricted effects in the reduced-form model. 
Overall, our benchmark identification of the matrix A looks as follows:

$$
A=\left(\begin{array}{ccccccc}
1 & \alpha_{12}<0 & \alpha_{13}<0 & -1<\beta_{14}<0 & 0 & 0 & \gamma_{17} \\
\alpha_{21} & 1 & \alpha_{23} & 0 & -1<\beta_{25}<0 & 0 & \gamma_{27} \\
\alpha_{31}>0 & \alpha_{32}>0 & 1 & 0 & 0 & -1<\beta_{36}<0 & \gamma_{37} \\
-1<\beta_{41}<0 & 0 & 0 & 1 & \alpha_{45}<0 & \alpha_{46}<0 & \gamma_{47} \\
0 & -1<\beta_{52}<0 & 0 & \alpha_{54} & 1 & \alpha_{56} & \gamma_{57} \\
0 & 0 & -1<\beta_{63}<0 & \alpha_{64}>0 & \alpha_{65}>0 & 1 & \gamma_{67} \\
\gamma_{71} & \gamma_{72}>0 & \gamma_{73}>0 & \gamma_{74} & \gamma_{75}<0 & \gamma_{76}<0 & 1
\end{array}\right)
$$

This matrix A is used for the estimation of our benchmark model. Recall again that most of these assumptions are used merely to help us identify the "correct" rotation of the matrix $A$, which represents the underlying economic relationships. Indeed, as will become evident below, most of them are not binding, so they are only helping us determine which rotation is the one that is meaningful and consistent with the theory.

\section{III.4 Controlling for common shocks and identified macro shocks}

Recall that one of the central conditions to achieve identification is that the structural-form shocks are orthogonal to one another, i.e. $E_{t}\left(\mu_{i, t} \mu_{j, t}\right)=0$. In reality, this condition may not be fulfilled, in particular if asset price shocks are driven by common shocks, as indicated by the vector $z_{t}$ in equation (1). Common shocks for asset prices within a country may be news about economic fundamentals in the respective country, such as announcements of releases of relevant macroeconomic data. As discussed in section II., the literature has analyzed and tested for the role of macroeconomic news extensively and found strong evidence for the importance of such news for asset prices. Moreover, there may be common shocks for international asset prices, such as oil price shocks.

We address the issue of common shocks in three separate ways in order to ensure the orthogonality of the structural-form shocks. First, we include in our empirical model a set of macroeconomic news in the United States and the euro area. Money Market Services (MMS) International conducts a weekly survey in which it asks market participants about their expectations about upcoming macroeconomic data releases. Based on these expectations data, we obtain the news component of each release, which is the difference between the actual announcement and its expectations. Our data includes a broad set of the most important macroeconomic news for the United States: the NAPM / ISM index of purchasing managers and consumer confidence; non-farm payroll employment and unemployment figures; average workweek, GDP, and industrial production; retail sales, trade balance and housing start 
figures; as well as PPI and CPI releases. For the euro area, our set of news includes those for the euro area since 1999 as well as for Germany going back to the early 1990s: The Ifo business climate, business and consumer confidence indices; GDP, industrial production and manufacturing orders; unemployment, retail sales and trade balance figures; and news about M3, PPI and CPI numbers. A detailed analysis and background of the included data is provided in Ehrmann and Fratzscher (2004b). In addition to these macroeconomic news, we include oil price changes in order to control for such shocks which are likely to influence most if not all of the asset prices included. However, a key difficulty for addressing the issue of common shocks is that such shocks are partly unobservable.

Our second way of dealing with common shocks is therefore to include a common factor in the structural-form model (1). The third way is mainly to test directly whether or not common shocks are important. To do so, we need to define more than 2 heteroskedastic regimes - which implies an over-identification of the model, as discussed above. In fact, in our empirical application we were able to uncover 15 separate regimes. If there are common shocks in the data that have not been modeled, the test for the overidentifying restrictions should be rejected. The intuition is the following: the procedure to identify the coefficients is based on a rotation of the distribution of the residuals that is explained entirely by changes in the variances of the shocks and not by changes in the endogenous coefficients (matrix A). When the model is misspecified in the sense that there are more common shocks than the ones modeled, then there are rotations of the residuals that cannot be explained by the coefficients and the shocks in the model. In other words, there are rotations that cannot be matched with the structure imposed. In these circumstances, the overidentifying restrictions are rejected. ${ }^{3}$

\section{Results}

The empirical analysis focuses on financial linkages between the US and the euro area money markets, bonds markets, equity markets and foreign exchange markets in the period 19892004. For the United States, we include the three-month Treasury-bill rate for the short rate, the ten-year Treasury-bond rate for the long rate, and the S\&P 500 index for the stock market. For the euro area, we use the three-month interbank rate - the FIBOR rate before 1999 and the EURIBOR after 1999 - for the short rate, the German ten-year government bond for the long rate, and the S\&P Euro index for the equity market. ${ }^{4}$ The exchange rate included is the US dollar - Deutsche mark before 1999 and the US dollar - euro since 1999. ${ }^{5}$ We use the

\footnotetext{
${ }^{3}$ See Rigobon and Sack (2003) for a discussion on the importance of common shocks in the context of monetary policy and the stock market.

${ }^{4}$ The results presented below are robust to using other variables, such as one-month interest rates and using German equity indices instead of the euro area index.

${ }^{5}$ The US dollar - Deutsche mark exchange prior to 1999 is multiplied with the Deutsche mark - euro conversion rate.
} 
annualized return series of each asset price in our empirical model. Looking at the daily return series confirms that all of them exhibit the typical characteristics of heteroskedasticity, skewness and excess kurtosis.

A further important issue is that of the data frequency and timing. Trading in the European markets takes place earlier than in the United States, which implies that shocks emanating from the European markets are always incorporated into US asset prices on the same day. By contrast, since there is only a limited overlap in trading times between the US and the euro area markets (especially for the short rates, as the closing quotes for the German and euro area markets are determined at 11:00 Central European Time), some of the US shocks only affect European asset prices on the subsequent business day. To reduce this problem of only partial overlap of trading times, we change the frequency of the analysis and use two-day returns for all of the asset return series. ${ }^{6}$

As discussed in section III.1, we argue that standard identification techniques are not adequate to solve the problem at hand. Table 1 shows the results that are obtained with the standard Cholesky decompositions and, alternatively, a VAR approach using sign restrictions. For simplicity, we decided to model only the domestic subsystems separately; as we see from the results, even these smaller subsystems cannot be properly identified in this fashion. For the Cholesky decompositions, it is necessary to impose three zero-restrictions on the system. Given the endogeneity of asset prices, however, it is not at all obvious which parameters can be reasonably restricted to zero. We have tried all combinations, and report how the nonrestricted parameters change as a result. It turns out that the three zero-restrictions are in most cases able to pin down the other, non-restricted, parameters reasonably well, although this is not true for, e.g., $\alpha_{13}, \alpha_{23}$ or $\alpha_{46}$. Furthermore, each of these results is, in our view, implausible, as it is based on the assumption that three other parameters are equal to zero.

Table 1 here

We have also tested whether sign restrictions alone could be employed instead, by imposing the same sign restrictions that we introduced in section III.3, as well as $\alpha_{21}, \alpha_{54}<0$ and $\alpha_{23}, \alpha_{56}>0$. These assumptions identify a parameter space, the borders of which are reported in the second set of columns in Table 1. It is obvious that the range of parameters that is admissible under these restrictions is extremely large, and in many cases extends all the way to zero, where the sign restrictions become binding, such that it is not possible to identify

\footnotetext{
${ }^{6}$ This cannot eliminate the problem entirely, but it reduces its importance, as the relative share of the non-overlapping time periods is smaller in a two-day window. As we will show below, the results are robust to using lower frequencies, such as weekly data.
} 
the parameters of interest with this methodology either. In the following subsections, we will therefore report the results obtained with our alternative identification scheme.

\section{IV.1 Domestic transmission}

We start by presenting the estimates for the domestic asset price spillovers first, before moving on to the international linkages in the subsequent sub-section. We highlight parameters that are significant at the 95\% level through bold font. A more formal analysis of the significance is given in Tables 2 and 3 as well as Figures 1 and 2, which synthesize the results of 500 bootstrap replications. The significance is tested through the share of parameter values in the distributions depicted in Figures 1 and 2 that are beyond zero, or the share of replications in which the parameter restrictions are binding. ${ }^{7}$ The bootstrap is performed as follows: for each of the heteroskedasticity regimes, we have estimated the corresponding covariance matrices. We use these to create new data in each bootstrap replication that have the same covariance structure. For each draw, we estimate the coefficients by minimizing the moments given the restrictions. If the restrictions are binding, the estimated parameters will be close to the constraint in several replications, and will thus show up in the parameter distribution over all draws as a large mass in the vicinity of the constraint. ${ }^{8}$

Tables 2-3 and Figures 1-2 around here

\section{Direct effects:}

The following set of equations presents the results for the contemporaneous spillovers for the three US asset returns in the structural-form model (1):

$$
\begin{aligned}
r_{t}^{U S} & =\mathbf{0 . 1 7 1 4} \cdot b_{t}^{U S}+\mathbf{0 . 0 1 1 3} \cdot s_{t}^{U S}+\ldots \\
b_{t}^{U S} & =\mathbf{0 . 6 1 5 0} \cdot r_{t}^{U S}-\mathbf{0 . 0 1 4 6} \cdot s_{t}^{U S}+\ldots \\
s_{t}^{U S} & =\mathbf{- 0 . 7 5 7 5} \cdot r_{t}^{U S}-0.1469 \cdot b_{t}^{U S}+\ldots
\end{aligned}
$$

For the euro area, the results for the three asset prices are as follows:

$$
r_{t}^{E A}=\mathbf{0 . 1 4 7 4} \cdot b_{t}^{E A}+0.0010 \cdot s_{t}^{E A}+\ldots
$$

\footnotetext{
${ }^{7}$ Interestingly, none of our "no magnification" restrictions which set the parameters of international market-spillovers to be below one are ever binding.
} 


$$
\begin{aligned}
b_{t}^{E A} & =\mathbf{0 . 2 7 7 1} \cdot r_{t}^{E A}+0.0001 \cdot s_{t}^{E A}+\ldots \\
s_{t}^{E A} & =\mathbf{- 2 . 0 8 8 8} \cdot r_{t}^{E A}-\mathbf{0 . 5 3 2 8} \cdot b_{t}^{E A}+\ldots
\end{aligned}
$$

Recall that the estimates of these structural-form equations can be interpreted as the direct effects of the various shocks, thus not incorporating possible indirect effects via other asset prices. The overall conclusion is that all there are significant contemporaneous linkages across US asset prices and across euro area asset prices, all these relations have the expected sign, and most of these are statistically significant. The question is whether the parameter estimates and relationships can be interpreted in a meaningful way.

Equations (3) and (6) can be understood as high-frequency monetary policy reaction functions that reflect market expectations about the implications of other asset prices movements for future monetary policy. The estimate for the United States indicates a response of short-term interest rates by 17 basis points (bp) to a $100 \mathrm{bp}$ shock to the bond yield (equation (3)). As bond yields to some extent capture inflationary expectations - and to some extent expectations of changes in real interest rates, as triggered, e.g., by anticipations of higher economic growth - this effect seems rather small, but nevertheless highly significant. For the euro area, we find a response of similar magnitude with $15 \mathrm{bp}$.

Turning to the second part of the equations, a $1 \%$ rise in equity prices in the United States induces a rise of US short rates by $1 \mathrm{bp}$. Given the large magnitude of equity movements in particular over the last few years, this result suggests that US monetary policy indeed responds significantly to equity markets. By contrast, for the euro area the short rate is estimated to rise by only $0.1 \mathrm{bp}$ to a $1 \%$ increase in equity prices, a result that is substantially smaller than that for the US equation, and also not statistically significant. This finding constitutes an interesting and arguably quite intuitive result as it suggests that US monetary policy is more responsive to equity markets than the monetary authorities in the euro area.

Equations (4) and (7) show the bond market equations. The estimates for the United States imply that yields rise by about $61 \mathrm{bp}$ due to a $100 \mathrm{bp}$ change in short rates, which is substantially larger than for the euro area, where a $100 \mathrm{bp}$ increase in short rates raises bond yields by only $28 \mathrm{bp}$. These responses might seem small, although one would expect that changes of short rates are often understood as temporary and thus only a modest fraction of such changes are transmitted to bond yields. Moreover, it has been argued in the literature that the response of long rates to monetary policy very much depends on the market perception of monetary policy. It has been found that in an environment where a tightening in monetary policy is perceived as credible and effective in lowering inflation, long rates may actually fall

\footnotetext{
${ }^{8}$ For example, a constraint that is sometimes binding is that a coefficient is restricted to be positive or negative. When this constraint is binding, the estimates are smaller than $10^{\wedge}-5$. Hence, in the
} 
(Thornton 1998). Hence, the relatively small sensitivity of bond yields to changes in shortterm interest rates may be convincing and underlines the credibility of monetary policy in the United States and in the euro area in containing inflationary pressures.

The other estimates of equations (4) and (7) indicate that US bond yields fall by $1 \mathrm{bp}$ due to a $1 \%$ increase in US stock prices, whereas there is basically no response of bond yields in the euro area. Again, the relatively large movements in equity markets in recent years make this estimate appear plausible. As to the sign of the parameter estimates, it appears that bond yields drop in response to equity markets strengthening because of a portfolio rebalancing.

Equations (5) and (8) present the stock market equations and their responses to shocks in domestic short-term and in long-term interest rates. Stock prices in the United States are estimated to fall by $0.76 \%$ in response to a $100 \mathrm{bp}$ rise in short-term rates, and do not respond significantly to an increase in long rates. These effects are larger for the euro area, where stock markets decline by $2.09 \%$ and $0.53 \%$ in response to a 100 bp rise in short rates and in long rates, respectively.

Asset price models usually model equity prices as the discounted sum of future dividends, and therefore a rise in interest rates implies an increase in the discount rate and a drop in equity prices. It should be noted that these estimates are smaller than those found in the literature for the United States (e.g. Rigobon and Sack 2002, Bernanke and Kuttner 2004, Ehrmann and Fratzscher 2004a), although these papers use different methodologies and analyze different time periods. An interesting point to note is that long rates have a substantially, almost three times smaller effect on stock markets than short-term interest rates in the United States and only about half the effect in the euro area. The rationale for this finding is quite intuitive as changes in equity prices are not only caused by changes in the discount factor but also by changes in cash flows and/or risk preferences. Andersen, Bollerslev, Diebold and Vega (2004) argue that cash flow effects on equity markets are significant and dominate in recessionary periods over discount rate effects. A rise in shortterm interest rates is likely to have little effect on cash flows over the long-run whereas an increase in bond yields may at least in part reflect an improved outlook for growth and hence expectations of higher cash flows. Therefore in the case of bond yields, the negative effect of a rise in the discount factor is partly offset by the positive effect of improved earnings expectations, thus resulting in a smaller direct effect of bonds on stock returns.

Overall effects: 
Through the reduced-form model (2), we can trace the overall effect of any given structural shock on the variables in our model, after accounting for instantaneous spillovers through all markets. For the domestic transmission parameters in the US, the results are as follows:

$$
\begin{aligned}
r_{t}^{U S} & =\mathbf{1 . 2 5 1 4 0} \cdot \mu_{r, t}^{U S}+\mathbf{0 . 2 6 2 7} \cdot \boldsymbol{\mu}_{b, t}^{U S}+\mathbf{0 . 0 0 8 9} \cdot \mu_{s, t}^{U S}+\ldots \\
b_{t}^{U S} & =\mathbf{1 . 0 2 4 0} \cdot \mu_{r, t}^{U S}+\mathbf{1 . 4 3 0 0} \cdot \mu_{b, t}^{U S}-0.0102 \cdot \mu_{s, t}^{U S}+\ldots \\
s_{t}^{U S} & =-\mathbf{1 . 1 0 1 2} \cdot \mu_{r, t}^{U S}-\mathbf{0 . 4 0 8 3} \cdot \mu_{b, t}^{U S}+\mathbf{0 . 9 9 6 4} \cdot \mu_{s, t}^{U S}+\ldots
\end{aligned}
$$

With the results for the euro area:

$$
\begin{aligned}
r_{t}^{E A} & =\mathbf{0 . 9 3 6 3} \cdot \mu_{r, t}^{E A}+\mathbf{0 . 2 3 2 6} \cdot \mu_{b, t}^{E A}+0.0009 \cdot \mu_{s, t}^{E A}+\ldots \\
b_{t}^{E A} & =0.3909 \cdot \mu_{r, t}^{E A}+\mathbf{1 . 3 2 4 5} \cdot \mu_{b, t}^{E A}+0.0003 \cdot \mu_{s, t}^{E A}+\ldots \\
s_{t}^{E A} & =0.0034 \cdot \mu_{r, t}^{E A}-\mathbf{1 . 1 3 7 0} \cdot \mu_{b, t}^{E A}+\mathbf{1 . 0 0 1 3} \cdot \mu_{s, t}^{E A}+\ldots
\end{aligned}
$$

The results are remarkably similar to those reported for the direct effects. US and euro area short rates respond to shocks to the long rates in a similar magnitude, increasing rates when inflation expectations rise. Also, both economies are characterized by a very small effect of stock market shocks to short rates. This model also mirrors the differential responses of long rates to the short rates we had seen earlier: for the US, we find a very strong (near one-to-one) reaction, whereas euro area rates respond much less.

An interesting difference relates to the response of stock markets to shocks in short rates, though. Whereas the direct response discussed above is larger in the euro area compared to the US, this difference is reversed when it comes to the overall effect: stock markets in the euro area do not respond to shocks to short rates overall, whereas we find a $1 \%$ decline in stock prices in the US in response to a $100 \mathrm{bp}$ rise in short rates.

\section{IV.2 International transmission}

We now turn to the international spillovers of asset price shocks in our model.

\section{Direct effects:}

As discussed above, we restrict all parameters that relate to international spillovers across different markets to zero in the structural-form model, such that we will only report those parameters that show international spillover effects across the same markets, as well as those 
for the exchange rate. US asset returns respond to their euro area counterparts and the exchange rate in the following way:

$$
\begin{aligned}
r_{t}^{U S} & =0.2123 \cdot r_{t}^{E A}+\mathbf{0 . 0 3 6 8} \cdot e_{t}+\ldots \\
b_{t}^{U S} & =\mathbf{0 . 5 5 1 2} \cdot b_{t}^{E A}+\mathbf{0 . 0 1 1 7} \cdot e_{t}+\ldots \\
s_{t}^{U S} & =0.0022 \cdot s_{t}^{E A}-0.0081 \cdot e_{t}+\ldots
\end{aligned}
$$

whereas the spillovers from the United States to the euro area look as follows:

$$
\begin{aligned}
r_{t}^{E A} & =\mathbf{0 . 2 9 9 7} \cdot r_{t}^{U S}-\mathbf{0 . 0 6 0 0} \cdot e_{t}+\ldots \\
b_{t}^{E A} & =\mathbf{0 . 3 0 3 2} \cdot b_{t}^{U S}-0.0079 \cdot e_{t}+\ldots \\
s_{t}^{E A} & =\mathbf{0 . 6 1 4 3} \cdot s_{t}^{U S}+\mathbf{0 . 5 7 6 6} \cdot e_{t}+\ldots
\end{aligned}
$$

Although we restrict all the parameters for the international spillovers across the same markets to be between zero and one, none of the restrictions is actually binding. The spillovers from the US to the euro area are generally larger than in the other direction, with the notable exception of the bond yields. The most extreme difference in this respect is found for the stock markets, with a spillover of 0.61 from the US to the euro area, and a statistically insignificant effect of euro area markets on US equity markets. These estimates indeed seem plausible, given the generally observed leading role of the US stock markets.

As to the effects of the exchange rate, a depreciation of the US dollar leads to an increase in short-term interest rates, as would be expected if monetary policy responded to the exchange rate. ${ }^{9}$ For the euro area, we get a larger effect, which seems intuitive. The most interesting effect is found for equity markets. Whereas US equity markets do not respond to exchange rate movements, the euro area markets rise by a substantial amount following an appreciation of the euro: a $10 \%$ appreciation of the euro is estimated to induce a $5.7 \%$ rise in euro area equity prices.

\section{Overall effects:}

Focusing on the reduced-form model (2) allows us to understand and analyze the overall spillovers, including both direct and indirect effects. The following equations show the estimates for the contemporaneous spillovers from euro area assets and the exchange rate to the three US asset returns:

\footnotetext{
9 The exchange rate is defined as US dollar in units of euro, i.e. an appreciation of the US dollar is a fall in the exchange rate.
} 


$$
\begin{aligned}
& r_{t}^{U S}=\mathbf{0 . 4 4 3 1} \cdot \mu_{r, t}^{E A}+\mathbf{0 . 2 0 9 9} \cdot \mu_{b, t}^{E A}+\mathbf{0 . 0 0 0 5} \cdot \mu_{s, t}^{E A}+\mathbf{0 . 0 2 1 1} \cdot \mu_{e, t}+\ldots \\
& b_{t}^{U S}=\mathbf{0 . 5 4 4 3} \cdot \mu_{r, t}^{E A}+\mathbf{0 . 8 6 8 2} \cdot \mu_{b, t}^{E A}+0.0005 \cdot \mu_{s, t}^{E A}+0.0154 \cdot \mu_{e, t}+\ldots \\
& s_{t}^{U S}=\mathbf{- 0 . 4 5 0 2} \cdot \mu_{r, t}^{E A}-\mathbf{0 . 2 9 2 3} \cdot \mu_{b, t}^{E A}+0.0018 \cdot \mu_{s, t}^{E A}-0.0232 \cdot \mu_{e, t}+\ldots
\end{aligned}
$$

And for the spillovers from the United States to the euro area, the results are as follows:

$$
\begin{aligned}
r_{t}^{E A} & =\mathbf{0 . 4 4 8 7} \cdot \mu_{r, t}^{U S}+\mathbf{0 . 1 7 2 6} \cdot \mu_{b, t}^{U S}+\mathbf{0 . 0 0 6 2} \cdot \mu_{s, t}^{U S}-\mathbf{0 . 0 3 8 9} \cdot \mu_{e, t}+\ldots \\
b_{t}^{E A} & =\mathbf{0 . 4 3 6 4} \cdot \mu_{r, t}^{U S}+\mathbf{0 . 4 8 4 5} \cdot \mu_{b, t}^{U S}-0.0010 \cdot \mu_{s, t}^{U S}-0.0120 \cdot \mu_{e, t}+\ldots \\
s_{t}^{E A} & =-\mathbf{1 . 9 5 4 1} \cdot \mu_{r, t}^{U S}-\mathbf{1 . 0 9 5 7} \cdot \mu_{b, t}^{U S}+\mathbf{0 . 5 7 0 5} \cdot \mu_{s, t}^{U S}+\mathbf{0 . 4 9 6 7} \cdot \mu_{e, t}+\ldots
\end{aligned}
$$

The key finding is that not only the international transmission of shocks is significant for the large majority of asset prices, but that there are substantial international cross-market linkages. This underlines and confirms our argument that a more complete understanding of financial linkages requires the modeling of international cross-market financial linkages, which so far has been missing in the literature. The importance of the international crossmarket transmission of shocks manifests itself not only through the significance of the point estimates of the cross-market coefficients in equations (21)-(26), but also through the changes in the coefficients of the within-market coefficients - i.e. the international spillovers within equity markets, money markets and bond markets - when comparing the results of the structural-form model (15)-(20) and those of the reduced-form model (21)-(26).

In general, the results show that reactions to shocks emanating abroad are smaller than those to domestic shocks. It is also the case that US shocks are generally more influential for euro area markets than euro area shocks for US markets. Moreover, spillovers are largest within the same asset class and we find that the estimates have the expected sign and magnitude.

For equations (21) and (24) for short-term interest rates, one would expect that a positive shock to short rates, long rates or equity prices in the foreign markets should raise short-term interest rates at home, which we find to be true. In line with the domestic results, we find that shocks to the equity markets are not particularly relevant for short rates.

A more interesting finding is present in equations (22) and (25) for US and euro area bond yields. The estimates suggest that there are significant spillover effects across bond markets of these two economies, exceeding by far those of the money markets. This points to a large degree of co-movement of bond rates due to international portfolio allocation. A 
somewhat unexpected finding is that the spillover in bond markets from the euro area to the United States is large at 0.86 and also larger than in the opposite direction. It is hard to explain the strength of this spillover, although the sizeable net bond flows from the euro area to the United States since the mid-1990s may be a contributing factor. An interesting difference compared to the results obtained in the structural form relates to the effects of short rates on bond yields. Despite being restricted to zero in the structural form, the coefficients are large and highly significant in the reduced-form, as the effects of long rates on short rates within each economy and from short rates to long rates across countries are sizeable.

Highly interesting and revealing results are found for the equity market equations (23) and (26). Here we find large spillovers from all asset prices in the United States to the euro area. The effects from equity markets to equity markets mirror those found for the structural form. On average, a $1 \%$ shock to US equities leads to a corresponding adjustment of euro area equity prices of $0.57 \%$. By contrast, the spillover from euro area equities to US stock markets is very small and not statistically significant. This confirms the central role that US equity markets play in world stock markets.

Moreover, euro area equities are found to respond significantly to shocks in shortterm rates and bond yields in the United States. In fact, a 100 bp rise in US short rates is estimated to lower euro area equity prices by nearly $2 \%$. Again, this effect is the total effect of US short rates on euro area equities and implies that the channel of transmission can be manifold. First, a rise in US interest rates is likely to induce a similar movement in euro area short rate and bond yields. Second, there may be a direct effect in that a rise in US interest rates leads to higher borrowing costs for many euro area firms, in particular those that are active internationally. And third, the effect of US interest rate changes may be transmitted to European markets via the exchange rate (we will analyze in the subsequent section to what extent the exchange rate responds to the various asset prices and shocks).

By contrast, euro area money and bond markets exhibit a smaller influence on US equity markets although the effects are mostly statistically significant. Both of the signs of the estimates are correct, indicating that higher short-term and long-term interest rates in the euro area lower US equity prices. In particular, shocks to euro area bond and money markets have a significant effect on all three US markets, with the strongest effect of euro area markets being exerted on US bond yields.

\section{IV.3 Response of the exchange rate}

\section{Direct effects:}

As the final step of the analysis, we turn to the effect of asset prices on the exchange rate. The estimates are: 


$$
\begin{aligned}
e_{t}^{U S D / E U R}= & \mathbf{- 1 . 7 0 9 5} \cdot r_{t}^{U S}-\mathbf{0 . 6 6 8 8} \cdot b_{t}^{U S}-\mathbf{0 . 0 7 7 6} \cdot s_{t}^{U S} \\
& +\mathbf{5 . 6 8 7 1} \cdot r_{t}^{E A}+0.0000 \cdot b_{t}^{E A}+0.0000 \cdot s_{t}^{E A}+\ldots
\end{aligned}
$$

Two of the restrictions we imposed on the exchange rate equation are actually binding: the response of exchange rates to euro area bond and equity yields is estimated to be zero. However, the estimates for the impact of short rates on the exchange rate are sensible. A 100 bp rise in US short rates leads to a $1.71 \%$ appreciation of the US dollar, whereas a $100 \mathrm{bp}$ increase in euro area shot-term interest rates induces a euro appreciation of 5.69\%. The difference between these two is quite large, implying that the exchange rate is about three times more sensitive to interest rate changes in the euro area. One possible explanation for such a difference is that the euro area economy is a more open one compared to the United States, although the difference in the point estimates is nevertheless striking. The exchange rate appreciates in response to increasing bond yields in the US, as well as in response to rising equity markets.

\section{Overall effects:}

Finally, it is interesting to note that, even though the restrictions were binding on the structural form, the overall effects from shocks to euro area bond yields and equity markets have the correct sign, and for bond yields even a comparable magnitude to the effects of shocks to the US bond yields. However, most parameters are not statistically significant:

$$
\begin{aligned}
e_{t}^{U S D / E U R}= & -0.1872 \cdot \mu_{r, t}^{U S}-0.3924 \cdot \mu_{b, t}^{U S}-0.0508 \cdot \mu_{s, t}^{U S} \\
& +\mathbf{4 . 2 3 8 3} \cdot \mu_{r, t}^{E A}+0.4062 \cdot \mu_{b, t}^{E A}+\mathbf{0 . 0 0 4 1} \cdot \mu_{s, t}^{E A}+\ldots
\end{aligned}
$$

These results suggest that the USD/EUR exchange rate overall responds mostly to developments in the euro area, in particular to euro area short-term interest rates and to some extent also euro area equity markets.

\section{IV.4 Variance decomposition}

Having identified and analyzed the domestic and international transmission of shocks, we now turn to assessing the relative, overall importance of each of the financial markets in the system. In particular, how much of developments in domestic financial markets are explained by shocks in foreign markets and how much is due to domestic factors? Moreover, what is the role of common shocks and the exchange rate?

In order to answer these questions in this section, we compute the variance decomposition implied by our estimates. Recall that the model is fully identified, and 
therefore a variance decomposition can be estimated. If we were using instrumental variables to estimate only some of the coefficients, this exercise would have been impossible. This is one of the advantages of the methodology presented here. Equation (1) defines the endogenous variables as

$$
A y_{t}=\vartheta+\Pi(L) y_{t-1}+\Psi(L) z_{t}+\mu_{t}
$$

where all coefficients have been estimated.

Two variance decompositions can be estimated, one in which the lags and exogenous variables are included, and one in which only the endogenous variables and shocks are included. The first one is computed as follows:

$$
\operatorname{var}\left(y_{t}\right)=\left(I-A^{-1} \Pi(L)\right)\left(\Psi(L) \operatorname{var}\left(z_{t}\right) \Psi^{\prime}(L)+\operatorname{var}\left(\mu_{t}\right)\right)\left(I-A^{-1} \Pi(L)\right)
$$

while the second one is

$$
\operatorname{var}\left(y_{t}\right)=\left(I-A^{-1} \Pi(L)\right) \operatorname{var}\left(\mu_{t}\right)\left(I-A^{-1} \Pi(L)\right)^{-1}
$$

Ultimately we are interested in understanding which shocks contribute the most in explaining the volatility of the endogenous variables. Both variance decompositions are very similar, and we present here the results from the second one. ${ }^{10}$

Table 4 here

Table 4 shows the variance decomposition for the reduced-form model (2) over the whole sample period 1989-2004. Each cell indicates the share of the total variance of each financial market that is explained by the respective shocks to the seven asset prices $\mu_{\mathrm{i}, \mathrm{t}}$ as well as the common shock $\mu_{\mathrm{c}, \mathrm{t}}$. As expected, by far the largest share of the respective variances is explained by the own idiosyncratic shocks, ranging between $55 \%$ and $97 \%$.

The key result is that a significant and relatively large share of the behavior of financial markets is explained by foreign asset prices. For the United States, about $8 \%$ of the variances of short-term interest rates are due to shocks in short-term rates, long-term rates or equity markets in the euro area. For the long rates, this share doubles as $16 \%$ of US bond

\footnotetext{
${ }^{10}$ Recall that our estimation includes a common shock.
} 
movements are accounted for by innovations to euro area financial markets. By contrast, a much larger share of euro area financial market movements are driven by US financial markets: $25 \%$ each of the variances of euro area short rates and long rates are explained by US financial market shocks. This share rises even to $27 \%$ for euro area equity markets.

Looking specifically at the international transmission of shocks, it is striking that US markets are much more important for euro area markets than vice versa. Particularly strong are the spillovers in equity markets: more than $22 \%$ of euro area equity market movements is due to US equity markets. A similar share of euro area short-term interest rate changes is explained by US short rates. By contrast, only about $6 \%$ of movements in US short rates is due to euro area short-term interest rate changes.

For the US, movements in euro area bond yields account for $12 \%$ of the variance of US bond yields. By contrast, shocks to US bond yields explain 15\% of the variance in euro area bond yields. This comparison also puts into perspective the different point estimates presented in the previous sub-section, where the estimates for the transmission in bond markets in the reduced-form model was 0.87 from the euro area to the US, and only 0.48 in the opposite direction. The variance decomposition shows that US bond markets are more important overall for euro area markets than vice versa, despite the smaller spillover coefficient. This difference between variance decomposition and point estimate stresses that over the whole sample period 1989-2004 financial markets in both regions were mostly driven by US shocks.

A final note concerns the role of exchange rate and common shocks, shown in the bottom two rows of the table. Exchange rates have a larger overall importance for euro area markets, accounting for $8 \%$ of movements in euro area short rates and $11 \%$ of euro area equity markets. The role of exchange rates for US markets is smaller, although common shocks seem to have a somewhat larger effect on US markets as compared to euro area markets.

In summary, the key finding is that US and euro area financial markets are closely linked, not only within asset classes but also across financial assets. On average, $26 \%$ of the variance of the three euro area financial assets is accounted for by US developments, whereas a still sizeable albeit smaller share of, on average, around $8 \%$ of US financial market movements are due to euro area developments.

\section{Robustness}

We now turn to robustness tests to check how the above results would change under alternative specifications of the model. In particular, we check the robustness of the results 
with regard to the 2-day time window and to variations over particular sub-periods in the sample.

We start by analyzing models with different time windows. As discussed above, the rationale for using a 2-day time window in our benchmark model is that a higher frequency window allows a much cleaner identification of shocks and their underlying regimes. The 2day window, rather than the daily window, was chosen because of the later trading time in the US which means that those US shocks that occur after the closing of European markets affect the latter only on the subsequent business day. ${ }^{11}$ As alternative specifications, we test the model using 3-day and 5-day windows. Table 5 shows the parameter estimates of the reduced-form and Table 6 for the variance decompositions of the model with a 5-day window.

Tables 5-6 here

For the model using a 5-day window, the sign and size of the parameter estimates are broadly in line with those of our benchmark model using a 2-day window. In some cases the point coefficients are smaller and less significant statistically. This is what one would expect given that the model with a 5-day window has about $60 \%$ less observations, and also given that it is more difficult to identify the different regimes with data points that span over longer periods. Moreover, the variance decomposition confirms the results of the benchmark results, in particular in that US markets are a very important driving force behind movements in euro area markets, while the transmission of shocks in the opposite direction is sizeable albeit overall much smaller.

As a second robustness check, we test whether the transmission of shocks across financial markets has changed significantly over time. A particularly relevant issue is whether EMU has led to a stronger integration between the euro area and the United States. Ideally one therefore would like to estimate the model over the period since monetary union in the euro area in 1999 and compare it to the pre-EMU period. However, since the period since EMU is too short to reliably estimate the parameters for each regime, we estimate the model over the pre-EMU period 1989-1998 and compare it to the benchmark model that includes the EMU period. The key finding is that almost all international transmission parameters are smaller, and in some cases substantially so, in the pre-EMU period 1989-1998 (Table 5, middle columns). The variance decomposition confirms this picture as domestic financial markets reacted substantially less to foreign financial markets in the pre-EMU period. Only on average $3.5 \%$ of the variance of US asset price movements was explained by euro area shocks in 1989-1998 as compared to about 8\% over the whole period 1989-2004 that includes

\footnotetext{
${ }^{11}$ It is important to recall that all our windows are non-overlapping.
} 
the EMU period. Similarly, the variance of euro area financial markets explained by US developments rises from about $10 \%$ in the pre-EMU period to on average $26 \%$ over the full sample period (Table 6, panel B). Overall, this indeed indicates that financial markets have become more integrated internationally since 1999. Of course, it should be stressed that this evidence is only suggestive as our model does not allow testing the effect of EMU directly and also does not allow identifying time variations of the transmission process over shorter periods of time.

As a further robustness check, we test whether the financial transmission process intensifies during periods of recessions as compared to expansions. We do this by estimating the model excluding recessions, as defined by the NBER recession dates. Table 5 reveals that almost all parameter estimates are lower when excluding the recessions. Moreover, Table 6 confirms this by indicating that the share of the variance explained by foreign financial market developments is lower when excluding recessions. Overall, these findings are again suggestive for the presence of time variations in the degree of financial integration, in particular the degree of the international transmission of shocks.

In summary, we find that there are some time variations in the degree of the transmission of shocks, in particular those between the United States and the euro area markets. Nevertheless, the important result of this section is that overall the conclusions drawn in section IV. about the direction and importance of the transmission of shocks is largely robust across the different specifications of the model.

\section{Conclusions}

The objective of the paper has been to measure and analyze the transmission of international financial shocks across markets as well as within countries. For a long time, academics, policy makers, and practitioners have known of these linkages. However, little research had been devoted to measuring them, and to understanding the extent to which they generate comovement across asset prices around the world. The literature mostly concentrated either on different markets within one country, or on one market across different countries. In this paper we have shown that indeed the transmission of shocks is highly complex, and that most transmission channels are significant and economically relevant. These findings are especially important for policy-makers in understanding the exposure to foreign financial market shocks, as well as for risk management and international portfolio diversification.

We have estimated in this paper the transmission of financial market shocks between the United States and the euro area over the 16-year period of 1989-2004. The results stress the importance of domestic as well as international spillovers, both within asset classes as well as across financial assets. While asset prices are found to react strongest to other 
domestic asset prices, we detect significant differences between the United States and the euro area in their financial market reaction functions to domestic financial shocks. In the United States, bond yields as well as equity markets are much more strongly affected by changes in short-term interest rates, which we interpret as expectations of monetary policy, than this is the case in the euro area. By contrast, euro area short rates and equity markets are relatively more affected by bond yields and exchange rates as compared to US markets. These findings thus identify some important differences in the financial transmission processes within the two economies, which may reflect differences in economic structure, in the degree of openness as well as different policy objectives.

The main results of the paper underline the importance of international spillovers, both within asset classes as well as across financial markets. Although the strongest international transmission of shocks takes place within asset classes, we find evidence that international cross-market spillovers are significant, both statistically as well as economically. For instance, shocks to US short-term interest rates exert a substantial influence on euro area bond yields and equity markets, and in fact explain as much as $10 \%$ of overall euro area bond market movements. But the transmission of shocks also runs in the opposite direction as in particular short-term interest rates of the euro area have a significant impact on US bond and equity markets. Overall, US financial markets explain on average more than $25 \%$ of euro area financial market movements in the period 1989-2004, whereas euro area markets account for $8 \%$ of the variance of US asset prices.

A second key result of the paper is that in almost all cases the direct transmission of financial shocks within asset classes is magnified substantially, mostly by more than $50 \%$, through indirect spillovers through other asset prices. For instance, the coefficient for the direct effect of shocks to US bond yields on euro area bond markets is 0.30 , but it rises to 0.48 when allowing for indirect spillovers of these shocks via other US and euro area asset prices.

Many open questions and avenues for future research remain. We have made several assumptions with the objective to being able to solve the problem of identification. Interpreting each asset price equation as a structural equation is one of them, assuming parameter stability to being able to use the estimation method is the second onset, and we made several sign and exclusion restrictions that allowed us to estimate the model. In the end, we find sensible patterns in the data, and uncover relatively robust results. Relaxing some of these assumptions and expanding the current model will certainly be fruitful avenues of future research. This paper hopes to be one step closer to the answer of how international markets are integrated. 


\section{References}

Andersen, T.G. and Bollerslev, T. (1998), "Deutsche Mark-Dollar Volatility: Intraday Activity Patterns, Macroeconomic Announcements, and Longer Run Dependencies," Journal of Finance, 53, 219-265.

Andersen, T.G., Bollerslev, T., Diebold, F.X. and Vega, C. (2003), "Micro Effects of Macro Announcements: Real-Time Price Discovery in Foreign Exchange," American Economic Review, 93, 38-62.

Andersen, T., Bollerslev, T., Diebold, F. and C. Vega (2004). Real-Time Price Discovery in Stock, Bond and Foreign Exchange Markets. Mimeo.

Bae, K.-H., Karolyi, A., Stulz, R., 2003. A New Approach to Measuring Financial Contagion. Review of Financial Studies, 16, 717-763.

Balduzzi, P., Elton, E.J. Green, T.C. (2001), "Economic News and Bond Prices: Evidence From the U.S. Treasury Market," Journal of Financial and Quantitative Analysis, 36, 523543.

Barsky, R. B. (1989), "Why Don't the Prices of Stocks and Bonds Move Together?," American Economic Review, 79, 1132-1145.

Becker, K. G., Finnerty, J. E. and Friedman, J. (1995), “Economic News and Equity Market Linkages between the U.S. and U.K.," Journal of Banking and Finance, 19, 1191-1210.

Becker, K.G., Finnerty, J.E., Gupta, M., (1990). The intertemporal relation between the U.S. and Japanese stock markets. Journal of Finance 45, 1297-1306.

Bernanke, B. S., and Kuttner, K. N. (2004), "What Explains the Stock Market's Reaction to Federal Reserve Policy," Journal of Finance, forthcoming.

Bollerslev, T., Cai, J. and Song, F.M. (2000), "Intraday Periodicity, Long Memory Volatility, and Macroeconomic Announcement Effects in the U.S. Treasury Bond Market," Journal of Empirical Finance, 7, 37-55.

Boyd, J. H., Jagannathan, R. and Hu, J. (2001), "The Stock Market's Reaction to Unemployment News: Why Bad News Is Usually Good For Stocks,” NBER Working Paper No. 8092.

Brooks, Robin and Marco del Negro (2002). "International Diversification Strategies." Working Paper 2002-23, Federal Reserve Bank of Atlanta.

Campbell, J.Y. and Ammer, J. (1993), "What Moves the Stock and Bond Markets? A Variance Decomposition for Long-Term Asset Returns," Journal of Finance, 48, 3-37.

Cass, D. and Pavlova, A. (2004), "On Trees and Logs," Journal of Economic Theory, 116, $41-83$. 
Connolly, R. and Wang, A. F. (2003), "International Equity Market Comovements: Economic Fundamentals or Contagion?" Pacific-Basin Finance Journal, 11, 23-43.

David, A. and Veronesi, P. (2004), "Inflation and Earnings Uncertainty and Volatility Forecasts" Manuscript, Graduate School of Business, University of Chicago.

Dungey, M., and V. L. Martin (2001): .Contagion Across Financial Markets: An Empirical Assessment,.Australian National University Mimeo.

Ehrmann, Michael and Marcel Fratzscher (2003). Monetary policy announcements and money markets: A transatlantic perspective, International Finance 6(3): 309-28.

Ehrmann, Michael and Marcel Fratzscher (2004a). Taking stock: Monetary policy transmission to equity markets, Journal of Money, Credit and Banking 36 (4): 719-37.

Ehrmann, Michael and Marcel Fratzscher (2004b). Equal size, equal role? Interest rate interdependence between the euro area and the United States, Economic Journal, forthcoming.

Ehrmann, Michael and Marcel Fratzscher (2004c). Exchange rates and fundamentals: new evidence from real-time data, Journal of International Money and Finance, forthcoming.

Eichengreen, Barry and Andrew Rose (1999). "Contagious Currency Crises: Channels of Conveyance." In Takatoshi Ito and Anne Krueger, eds., Changes in Exchange Rates in Rapidly Developing Countries: Theory, Practice, and Policy Issues. Chicago: University of Chicago Press, pp. 29-50.

Engle, R.F. (2002), "Dynamic Conditional Correlation: A Simple Class of Multivariate Generalized Autoregressive Conditional Heteroskedasticity Models," Journal of Business and Economic Statistics, 20, 339-350.

Engle, R.F., Ito, T. and Lin, W.L. (1990), "Meteor-Showers or Heat Waves - Heteroskedastic Intradaily Volatility in the Foreign Exchange Market,"Econometrica, 55, 391-407.

Fair, R. (2003), "Shock Effects on Stocks, Bonds and Exchange Rates", Journal of International Money and Finance, 22, 307-341.

Faust, J., Rogers, J., Wang, S., Wright, J. (2003), "The High Frequency Response of Exchange Rates and Interest Rates to Macroeconomic Announcements", Mimeo, October 2003.

Flannery, M. J. and Protopapadakis, A. (2002), "Macroeconomic Factors do Influence Aggregate Stock Returns," Review of Financial Studies, 15, 751-782.

Fleming, M.J. and Remolona, E.M. (1997), "What Moves the Bond Market," Economic Policy Review, Federal Reserve Bank of New York, 3 (December), 31-50.

Fleming, M.J. and Remolona, E.M. (1999), "Price Formation and Liquidity in the U.S. Treasury Market: The Response to Public Information," Journal of Finance, 54, 19011915. 
Forbes, K.J. and M. Chinn (2003). "A Decomposition of Global Linkages in Financial Markets Over Time", Review of Economics and Statistics, forthcoming..

Forbes, K.J. and R. Rigobon (2002). "No Contagion, Only Interdependence: Measuring Stock Market Co-Movements." The Journal of Finance 57 (5): 2223-2261.

Goldberg, L. and Leonard, D. (2003), "What Moves Sovereign Bond Markets? The Effects of Economic News on U.S. and German Yields," Current Issues in Economics and Finance, Federal Reserve Bank of New York, 9, 1-7.

Glick, Reuven and Andrew Rose (1999). "Contagion and Trade: Why Are Currency Crises Regional?" Journal of International Money and Finance 18: 603-617.

Griffin, J.M. and G. Andrew Karolyi (1998). "Another Look at the Role of the Industrial Structure of Markets for International Diversification Strategies." Journal of Financial Economics 50: 351-373.

Hamao, Y., Masulis, R.W. and Ng, V. (1990), "Correlations in Price Changes and Volatility Across International Stock Markets," Review of Financial Studies, 3, 281-307.

Hartmann, P. Straetmans, S. and C. de Vries (2003). Asset Market Linkages in Crisis Periods. Review of Economics and Statistics, forthcoming.

Heston, Steven L. and K. Geert Rouwenhorst (1994). "Does Industrial Structure Explain the Benefits of International Diversification?” The Journal of Finance 36:3-27.

Karolyi, G. Andrew and René M. Stulz (2002). “Are Financial Assets Priced Locally or Globally?" Forthcoming in George Constantinides, Milton Harris, and René M. Stulz, eds., Handbook of the Economics of Finance. North Holland.

King, M., Sentana, E.,Wadhwani, S., 1994. Volatility and links between national stock markets. Econometrica 62, 901-934.

King, M.A. and Wadhwani, S. (1990), "Transmission of Volatility between Stock Markets," Review of Financial Studies, 3, 5-33.

Kuttner, K.N. (2001), "Monetary Policy Surprises and Interest Rates: Evidence from the Fed Funds Futures Market," Journal of Monetary Economics, 47, 523-544.

Lin, W., Engle, R.F., Ito, T., 1994. Do bulls and bears move across borders? International transmission of stock returns and volatility. Review of Financial Studies 7, 507-538.

Pavlova, A. and R. Rigobon (2004). “Asset Prices and Exchange Rates”, Mimeo, MIT

Rigobon, R. (2003), “Identification Through Heteroskedasticity,” Review of Economics and Statistics, 85, 777-792.

Rigobon, R. and Sack, B. (2002), "The Impact of Monetary Policy on Asset Prices," NBER Working Paper No. 8794, Cambridge, Mass.

Rigobon, R. and Sack, B. (2003a), "Measuring the Reaction of Monetary Policy to the Stock Market," Quarterly Journal of Economics, 118, 639-669. 
Rigobon, R. and Sack, B. (2003b), "Spillovers Across U.S. Financial Markets," NBER Working Paper No. 9640, Cambridge, Mass.

Sentana, E. and G. Fiorentini (2001). "Identification, Estimation and Testing of Conditionally Heteroskedastic Factor Models", Journal of Econometrics, 102, 143-164.

Shiller, R. J. and Beltratti, A. E. (1992), "Stock Prices and Bond Yields," Journal of Monetary Economics, 30, 25-46.

Sims, C. (1980). "Macroeconomics and Reality", Econometrica, 48, 1-48.

Thornton, D.L. (1998). "Tests of the market's reaction to Federal funds rate target changes", Federal Reserve Bank of St. Louis Review, pp. 25-36.

Wright, P. (1928). "The Tariff on Animal and Vegetable Oils", Macmillan Company, New York.

Zapatero, F. (1995). "Equilibrium Asset Prices and Exchange Rates," Journal of Economic Dynamics and Control, 19, pp. 787-811. 
Table 1: Parameter estimates with traditional VAR methodologies

\begin{tabular}{lrrrr}
\hline \hline & \multicolumn{2}{c}{ Choleski decomposition } & \multicolumn{2}{c}{ Sign restrictions } \\
& $\min$ & $\max$ & $\min$ & $\max$ \\
\hline USA & & & & \\
$\alpha_{12}$ & 0.3998 & 0.4003 & -0.2964 & 0.0000 \\
$\alpha_{13}$ & 0.0707 & 0.2373 & -0.0435 & -0.0010 \\
$\alpha_{21}$ & 0.2901 & 0.2912 & -0.4016 & 0.0000 \\
$\alpha_{23}$ & -0.4166 & -0.3478 & 0.0069 & 0.0073 \\
$\alpha_{31}$ & 0.0010 & 0.0030 & 0.0000 & 2.9641 \\
$\alpha_{32}$ & -0.0073 & -0.0069 & 0.0000 & 0.4170 \\
Euro area & & & & \\
$\alpha_{45}$ & 0.3275 & 0.3327 & -0.2903 & -0.0204 \\
$\alpha_{46}$ & -0.8787 & -0.6168 & -0.0181 & 0.0000 \\
$\alpha_{54}$ & 0.1532 & 0.1551 & -1.1081 & 0.0000 \\
$\alpha_{56}$ & -0.8830 & -0.7874 & 0.0000 & 0.0070 \\
$\alpha_{64}$ & -0.0032 & -0.0022 & 0.0794 & 5.6990 \\
$\alpha_{65}$ & -0.0070 & -0.0059 & 0.0000 & 0.9244 \\
\hline \hline
\end{tabular}

Note: The table shows parameter estimates obtained through standard identification schemes. It reports the smallest and largest estimates that can be obtained by changing the order of variables in models identified through Choleski decompositions in the left panel, and the borders of the parameter space that is identified in a model with sign restrictions in the right panel. 
Table 2: Parameter estimates and bootstrap results of structural-form model

\begin{tabular}{|c|c|c|c|c|c|}
\hline & $\begin{array}{c}\text { point } \\
\text { estimate }\end{array}$ & & mean & $\begin{array}{l}\text { bootstrap } \\
\text { std. dev. }\end{array}$ & p-value \\
\hline \multicolumn{6}{|c|}{ Domestic transmission } \\
\hline \multicolumn{6}{|c|}{ USA } \\
\hline$\alpha_{12}$ & -0.1714 & $* * *$ & -0.1750 & 0.0493 & 0.0000 \\
\hline$\alpha_{13}$ & -0.0113 & $* * *$ & -0.0115 & 0.0036 & 0.0020 \\
\hline$\alpha_{21}$ & -0.6150 & $* * *$ & -0.5895 & 0.0651 & 0.0000 \\
\hline$\alpha_{23}$ & 0.0146 & $* * *$ & 0.0142 & 0.0045 & 0.0080 \\
\hline$\alpha_{31}$ & 0.7575 & $* * *$ & 0.7546 & 0.1377 & 0.0080 \\
\hline$\alpha_{32}$ & 0.1469 & $*$ & 0.1845 & 0.1649 & 0.0778 \\
\hline \multicolumn{6}{|c|}{ Euro area } \\
\hline$\alpha_{45}$ & -0.1474 & $* *$ & -0.1413 & 0.0488 & 0.0140 \\
\hline$\alpha_{46}$ & -0.0010 & & -0.0022 & 0.0021 & 0.1397 \\
\hline$\alpha_{54}$ & -0.2771 & $* * *$ & -0.2969 & 0.0624 & 0.0020 \\
\hline$\alpha_{56}$ & 0.0001 & & -0.0004 & 0.0028 & 0.5509 \\
\hline$\alpha_{64}$ & 2.0888 & $* * *$ & 2.0737 & 0.1403 & 0.0000 \\
\hline$\alpha_{65}$ & 0.5328 & $* * *$ & 0.5908 & 0.2290 & 0.0020 \\
\hline \multicolumn{6}{|c|}{ International transmission } \\
\hline \multicolumn{6}{|c|}{ US to euro area } \\
\hline$\beta_{41}$ & -0.2997 & $* * *$ & -0.2551 & 0.0890 & 0.0100 \\
\hline$\beta_{52}$ & -0.3032 & $* * *$ & -0.2957 & 0.0535 & 0.0000 \\
\hline$\beta_{63}$ & -0.6143 & $* * *$ & -0.5817 & 0.0630 & 0.0000 \\
\hline \multicolumn{6}{|c|}{ Euro area to US } \\
\hline$\beta_{14}$ & -0.2123 & $*$ & -0.1535 & 0.0682 & 0.0599 \\
\hline$\beta_{25}$ & -0.5512 & $* * *$ & -0.5583 & 0.0508 & 0.0000 \\
\hline$\beta_{36}$ & -0.0022 & & -0.0362 & 0.0612 & 0.1517 \\
\hline \multicolumn{6}{|c|}{ Exchange rate effects } \\
\hline$\gamma_{17}$ & -0.0368 & $* * *$ & -0.0316 & 0.0070 & 0.0040 \\
\hline$\gamma_{27}$ & -0.0117 & $* *$ & -0.0123 & 0.0077 & 0.0399 \\
\hline$\gamma_{37}$ & 0.0081 & & 0.0180 & 0.0841 & 0.4291 \\
\hline$\gamma_{47}$ & 0.0600 & $* * *$ & 0.0591 & 0.0059 & 0.0000 \\
\hline$\gamma_{57}$ & 0.0079 & & 0.0072 & 0.0056 & 0.1118 \\
\hline$\gamma_{67}$ & -0.5766 & $* * *$ & -0.5577 & 0.0430 & 0.0000 \\
\hline$\gamma_{71}$ & 1.7095 & $* * *$ & 1.6754 & 0.1753 & 0.0000 \\
\hline$\gamma_{72}$ & 0.6688 & $* * *$ & 0.6701 & 0.1737 & 0.0080 \\
\hline$\gamma_{73}$ & 0.0776 & $* *$ & 0.0882 & 0.0431 & 0.0499 \\
\hline$\gamma_{74}$ & -5.6871 & $* * *$ & -5.6036 & 0.2020 & 0.0000 \\
\hline$\gamma_{75}$ & 0.0000 & & -0.0052 & 0.0212 & 0.8044 \\
\hline$\gamma_{76}$ & 0.0000 & & -0.0115 & 0.0190 & 0.4611 \\
\hline
\end{tabular}

Note: the table reports the parameter estimates of model (1) obtained in the identification through heteroskedasticity. $*, * *, * * *$ denote significance at the $90 \%, 95 \%$ and $99 \%$ level, respectively. The significance is judged through the p-value obtained in a bootstrap. 
Table 3: Parameter estimates and bootstrap results of reduced-form model

\begin{tabular}{|c|c|c|c|c|c|}
\hline & $\begin{array}{c}\text { point } \\
\text { estimate }\end{array}$ & & mean & $\begin{array}{l}\text { bootstrap } \\
\text { std. dev. }\end{array}$ & $\mathrm{p}$-value \\
\hline \multicolumn{6}{|c|}{ Domestic transmission } \\
\hline \multicolumn{6}{|c|}{ USA } \\
\hline$a_{11}$ & 1.2514 & $* * *$ & 1.2255 & 0.1264 & 0.0000 \\
\hline$a_{21}$ & 1.0240 & $* * *$ & 0.9799 & 0.2491 & 0.0000 \\
\hline$a_{31}$ & -1.1012 & $* * *$ & -1.1394 & 0.2757 & 0.0000 \\
\hline$a_{12}$ & 0.2627 & $* * *$ & 0.2699 & 0.1216 & 0.0040 \\
\hline$a_{22}$ & 1.4300 & $* * *$ & 1.4424 & 0.1982 & 0.0000 \\
\hline$a_{32}$ & -0.4083 & $* * *$ & -0.4916 & 0.2672 & 0.0080 \\
\hline$a_{13}$ & 0.0089 & $* *$ & 0.0092 & 0.0040 & 0.0140 \\
\hline$a_{23}$ & -0.0102 & $*$ & -0.0097 & 0.0065 & 0.0539 \\
\hline$a_{33}$ & 0.9964 & $* * *$ & 1.0098 & 0.0284 & 0.0000 \\
\hline \multicolumn{6}{|c|}{ Euro area } \\
\hline$a_{44}$ & 0.9363 & $* * *$ & 0.9145 & 0.0721 & 0.0000 \\
\hline$a_{54}$ & 0.3909 & $* * *$ & 0.4001 & 0.1407 & 0.0040 \\
\hline$a_{64}$ & 0.0034 & & -0.0473 & 0.2135 & 0.7645 \\
\hline$a_{45}$ & 0.2326 & $* * *$ & 0.2275 & 0.0928 & 0.0000 \\
\hline$a_{55}$ & 1.3245 & $* * *$ & 1.3370 & 0.1470 & 0.0000 \\
\hline$a_{65}$ & -1.1370 & $* * *$ & -1.2663 & 0.3830 & 0.0000 \\
\hline$a_{46}$ & 0.0009 & & 0.0018 & 0.0019 & 0.1816 \\
\hline$a_{56}$ & 0.0003 & & 0.0011 & 0.0038 & 0.4092 \\
\hline$\underline{a_{66}}$ & 1.0013 & $* * *$ & 1.0211 & 0.0276 & 0.0000 \\
\hline \multicolumn{6}{|c|}{ International transmission } \\
\hline \multicolumn{6}{|c|}{ US to euro area } \\
\hline $\mathrm{b}_{41}$ & 0.4487 & $* * *$ & 0.4016 & 0.1323 & 0.0000 \\
\hline $\mathrm{b}_{51}$ & 0.4364 & $* * *$ & 0.4231 & 0.1649 & 0.0000 \\
\hline $\mathrm{b}_{61}$ & -1.9541 & $* * *$ & -1.9380 & 0.3407 & 0.0000 \\
\hline$b_{42}$ & 0.1726 & $* * *$ & 0.1707 & 0.0736 & 0.0000 \\
\hline$b_{52}$ & 0.4845 & $* * *$ & 0.4901 & 0.1635 & 0.0000 \\
\hline$b_{62}$ & -1.0957 & $* * *$ & -1.1632 & 0.3418 & 0.0000 \\
\hline $\mathrm{b}_{43}$ & 0.0062 & $* * *$ & 0.0067 & 0.0024 & 0.0000 \\
\hline $\mathrm{b}_{53}$ & -0.0010 & & -0.0002 & 0.0028 & 0.4371 \\
\hline$b_{63}$ & 0.5705 & $* * *$ & 0.5414 & 0.0618 & 0.0000 \\
\hline \multicolumn{6}{|c|}{ Euro area to US } \\
\hline $\mathrm{b}_{14}$ & 0.4431 & $* * *$ & 0.3659 & 0.1297 & 0.0040 \\
\hline $\mathrm{b}_{24}$ & 0.5443 & $* * *$ & 0.5065 & 0.1714 & 0.0020 \\
\hline$b_{34}$ & -0.4502 & $*$ & -0.4342 & 0.2966 & 0.0619 \\
\hline$b_{15}$ & 0.2099 & $* * *$ & 0.2073 & 0.1047 & 0.0020 \\
\hline $\mathrm{b}_{25}$ & 0.8682 & $* * *$ & 0.8861 & 0.2116 & 0.0000 \\
\hline $\mathrm{b}_{35}$ & -0.2923 & $* * *$ & -0.3570 & 0.1821 & 0.0000 \\
\hline$b_{16}$ & 0.0005 & & 0.0012 & 0.0011 & 0.1018 \\
\hline $\mathrm{b}_{26}$ & 0.0005 & & 0.0010 & 0.0026 & 0.3293 \\
\hline $\mathrm{b}_{36}$ & 0.0018 & & 0.0367 & 0.0653 & 0.3174 \\
\hline \multicolumn{6}{|c|}{ Exchange rate effects } \\
\hline $\mathrm{c}_{71}$ & -0.1872 & & -0.3679 & 0.4822 & 0.1537 \\
\hline $\mathrm{c}_{72}$ & -0.3924 & $* *$ & -0.4272 & 0.2884 & 0.0200 \\
\hline $\mathrm{c}_{73}$ & -0.0508 & $*$ & -0.0546 & 0.0332 & 0.0639 \\
\hline $\mathrm{c}_{74}$ & 4.2383 & $* * *$ & 4.1953 & 0.2490 & 0.0000 \\
\hline $\mathrm{c}_{75}$ & 0.4062 & & 0.3577 & 0.3766 & 0.1118 \\
\hline $\mathrm{c}_{76}$ & 0.0041 & & 0.0154 & 0.0191 & 0.1178 \\
\hline $\mathrm{c}_{17}$ & 0.0211 & $* * *$ & 0.0197 & 0.0049 & 0.0060 \\
\hline $\mathrm{c}_{27}$ & 0.0154 & $* *$ & 0.0139 & 0.0081 & 0.0299 \\
\hline$c_{37}$ & -0.0232 & & -0.0128 & 0.0600 & 0.3912 \\
\hline $\mathrm{c}_{47}$ & -0.0389 & $* * *$ & -0.0393 & 0.0031 & 0.0000 \\
\hline$c_{57}$ & -0.0120 & $* * *$ & -0.0126 & 0.0045 & 0.0060 \\
\hline $\mathrm{c}_{67}$ & 0.4967 & $* * *$ & 0.4937 & 0.0456 & 0.0000 \\
\hline$c_{77}$ & 0.7340 & $* * *$ & 0.7403 & 0.0209 & 0.0000 \\
\hline
\end{tabular}

Note: the table reports the parameter estimates of model (2) obtained in the identification through heteroskedasticity. $* * *, * * *$ denote significance at the $90 \%, 95 \%$ and $99 \%$ level, respectively. The significance is judged through the p-value obtained in a bootstrap. 
Table 4: Variance decomposition of benchmark model

\begin{tabular}{lrrrrrrr}
\hline \hline & \multicolumn{1}{c}{$r_{t}{ }^{U S}$} & \multicolumn{1}{c}{$b_{t}{ }^{U S}$} & \multicolumn{1}{c}{$s_{t}{ }^{U S}$} & \multicolumn{1}{c}{$r_{t}{ }^{E A}$} & \multicolumn{1}{c}{$b_{t}{ }^{E A}$} & \multicolumn{1}{c}{$s_{t}{ }^{E A}$} & \multicolumn{1}{c}{$e_{t}$} \\
\hline$\mu_{r, t}$ US & $80.17 \%$ & $22.41 \%$ & $1.54 \%$ & $21.22 \%$ & $9.80 \%$ & $3.38 \%$ & $0.09 \%$ \\
$\mu_{b, t}$ US & $4.44 \%$ & $54.96 \%$ & $0.27 \%$ & $3.95 \%$ & $15.19 \%$ & $1.34 \%$ & $0.48 \%$ \\
$\mu_{s, t}$ US & $0.32 \%$ & $0.17 \%$ & $97.59 \%$ & $0.31 \%$ & $0.00 \%$ & $22.36 \%$ & $0.50 \%$ \\
$\mu_{r, t}{ }^{E A}$ & $6.11 \%$ & $3.85 \%$ & $0.16 \%$ & $56.16 \%$ & $4.78 \%$ & $0.00 \%$ & $27.10 \%$ \\
$\mu_{b, t}{ }^{E A}$ & $1.70 \%$ & $12.16 \%$ & $0.08 \%$ & $4.31 \%$ & $68.15 \%$ & $0.86 \%$ & $0.31 \%$ \\
$\mu_{s, t}{ }^{E A}$ & $0.00 \%$ & $0.00 \%$ & $0.00 \%$ & $0.01 \%$ & $0.00 \%$ & $60.26 \%$ & $0.00 \%$ \\
$\mu_{e, t}$ & $1.20 \%$ & $0.27 \%$ & $0.04 \%$ & $8.41 \%$ & $0.39 \%$ & $11.50 \%$ & $70.42 \%$ \\
$\mu_{c, t}$ & $6.05 \%$ & $6.17 \%$ & $0.33 \%$ & $5.63 \%$ & $1.70 \%$ & $0.30 \%$ & $1.10 \%$ \\
\hline \hline
\end{tabular}

Note: the table reports the share of the variance of each series that is explained by the various structural shocks. 
Table 5: Parameter estimates of reduced-form, alternative models

\begin{tabular}{|c|c|c|}
\hline & \multicolumn{2}{|c|}{$\overline{\text { 5-day window }}$} \\
\hline & $\begin{array}{c}\text { point } \\
\text { estimate }\end{array}$ & $\begin{array}{l}\text { bootstrap } \\
\text { p-value }\end{array}$ \\
\hline USA & & \\
\hline$a_{11}$ & 0.9917 & $* * * 0.0000$ \\
\hline $\mathrm{a}_{21}$ & 0.2531 & $* * * 0.0000$ \\
\hline $\mathrm{a}_{31}$ & -0.7523 & ** 0.0419 \\
\hline$a_{12}$ & 0.0031 & $* * \quad 0.0279$ \\
\hline$a_{22}$ & 0.5363 & $* * * 0.0000$ \\
\hline$a_{32}$ & -1.1155 & 0.1138 \\
\hline$a_{13}$ & 0.0735 & 0.1437 \\
\hline$a_{23}$ & 0.1888 & 0.4731 \\
\hline$a_{33}$ & 0.7499 & $* * * 0.0000$ \\
\hline
\end{tabular}

Euro area

\begin{tabular}{lrr}
$\mathrm{a}_{44}$ & $0.9892 * * *$ & 0.0000 \\
$\mathrm{a}_{54}$ & $0.4299 * * *$ & 0.0000 \\
$\mathrm{a}_{64}$ & $-0.7626 * *$ & 0.0120 \\
$\mathrm{a}_{45}$ & $0.0076 * *$ & 0.0399 \\
$\mathrm{a}_{55}$ & $1.0963 * * *$ & 0.0000 \\
$\mathrm{a}_{65}$ & $-1.1719 * *$ & 0.0499 \\
$\mathrm{a}_{46}$ & 0.0478 & 0.2994 \\
$\mathrm{a}_{56}$ & 0.0480 & 0.5649 \\
$\mathrm{a}_{66}$ & $1.0859 * * *$ & 0.0000 \\
\hline
\end{tabular}

US to euro area

$\begin{array}{lrr}\mathrm{b}_{41} & 0.3084 * * * & 0.0000 \\ \mathrm{~b}_{51} & 0.1810 * * * 0.0020 \\ \mathrm{~b}_{61} & -0.8599 * * * & 0.0080 \\ \mathrm{~b}_{42} & -0.0872 & 0.6048 \\ \mathrm{~b}_{52} & 0.0817 * * * 0.0020 \\ \mathrm{~b}_{62} & -1.1993 * * * 0.0040 \\ \mathrm{~b}_{43} & 0.0113 & 0.2455 \\ \mathrm{~b}_{53} & 0.0452 & 0.6148 \\ \mathrm{~b}_{63} & 0.4755 * * * & 0.0000\end{array}$

International transmission

$\begin{array}{crrrr}0.9579 * * * & 0.0000 & 0.9359 * * * & 0.0000 \\ 0.0594 * * & 0.0240 & 0.0296 & 0.1497 \\ -0.0022 & 0.3214 & 0.0004 & 0.4930 \\ 0.0904 * * & 0.0200 & 0.2309 * * * & 0.0000 \\ 1.0464 * * * & 0.0000 & 1.1006 * * * & 0.0000 \\ -0.0852 & 0.1737 & -0.3947 * * * & 0.0020 \\ 0.0022 & 0.2715 & 0.0049 * & 0.0519 \\ -0.0198 * * & 0.0299 & 0.0010 & 0.3194 \\ 1.0016 * * * & 0.0000 & 1.0476 * * * & 0.0000\end{array}$

Domestic transmission

$$
\begin{array}{r}
1.0411 * * * 0.0000 \\
0.2293 * * * 0.0100 \\
-0.6020 * * * 0.0020 \\
0.3195 * * * 0.0000 \\
1.1325 * * * 0.0000 \\
-0.9045 * * \quad 0.0240 \\
-0.0008 \quad 0.4910 \\
-0.0371 * * 0.0339 \\
1.0262 * * * 0.0000
\end{array}
$$$$
1.2015 * * * 0.0000
$$$$
0.7165 * * * 0.0000
$$$$
-0.1798 * * * 0.0000
$$$$
0.2787 * * * 0.0060
$$$$
1.2501 * * * 0.0000
$$$$
-0.0940 * * * 0.0040
$$$$
0.0007 \quad 0.4331
$$$$
-0.0174 * * 0.0379
$$$$
1.0109 * * * 0.0000
$$

\section{Euro area to US}

\begin{tabular}{lcccccc}
$\mathrm{b}_{14}$ & $0.0034 * *$ & 0.0160 & $0.1290 * *$ & 0.0319 & $0.2400 * * * 0.0040$ \\
$\mathrm{~b}_{24}$ & $0.1338 * * * 0.0100$ & $0.0882 * *$ & 0.0140 & $0.0866 * *$ & 0.0240 \\
$\mathrm{~b}_{34}$ & $-0.3866 * *$ & 0.0220 & $-0.5277 * * *$ & 0.0060 & $-0.3950 *$ & 0.0579 \\
$\mathrm{~b}_{15}$ & 0.0007 & 0.1038 & $0.1019 * *$ & 0.0120 & $0.1705 * * *$ & 0.0060 \\
$\mathrm{~b}_{25}$ & $0.4267 * * *$ & 0.0040 & $0.4117 * * *$ & 0.0000 & $0.5662 * * * 0.0000$ \\
$\mathrm{~b}_{35}$ & $-0.9273 * * *$ & 0.0020 & $-0.4860 * * *$ & 0.0000 & $-0.1215 * * * 0.0100$ \\
$\mathrm{~b}_{16}$ & 0.0284 & 0.1218 & -0.0014 & 0.1277 & 0.0021 & 0.2236 \\
$\mathrm{~b}_{26}$ & 0.1082 & 0.1138 & $-0.0075 * *$ & 0.0240 & -0.0011 & 0.6587 \\
$\mathrm{~b}_{36}$ & $0.0564 * *$ & 0.0160 & 0.0072 & 0.1617 & -0.0004 & 0.8443 \\
\hline \hline
\end{tabular}

Note: the table reports the parameter estimates of model (2) obtained in the identification through heteroskedasticity. $* * *, * * *$ denote significance at the $90 \%, 95 \%$ and $99 \%$ level, respectively. The significance is judged through the p-value obtained in a bootstrap. 
Table 6: Variance decomposition of alternative models

A. 5-day estimation window

\begin{tabular}{lrrrrrrr}
\hline \hline & \multicolumn{1}{c}{$r_{t}{ }^{U S}$} & \multicolumn{1}{c}{$b_{t}{ }^{U S}$} & \multicolumn{1}{c}{$s_{t}{ }^{U S}$} & \multicolumn{1}{c}{$r_{t}{ }^{E A}$} & \multicolumn{1}{c}{$b_{t}{ }^{E A}$} & \multicolumn{1}{c}{$s_{t}{ }^{E A}$} & \multicolumn{1}{c}{$e_{t}$} \\
\hline$\mu_{r, t}$ US & $89.34 \%$ & $3.15 \%$ & $4.77 \%$ & $11.05 \%$ & $2.88 \%$ & $4.70 \%$ & $1.99 \%$ \\
$\mu_{b, t}$ US & $0.00 \%$ & $34.88 \%$ & $25.82 \%$ & $2.18 \%$ & $1.45 \%$ & $22.50 \%$ & $21.00 \%$ \\
$\mu_{s, t}$ US & $6.26 \%$ & $22.38 \%$ & $60.39 \%$ & $0.19 \%$ & $2.29 \%$ & $18.31 \%$ & $14.70 \%$ \\
$\mu_{r, t}{ }^{E A}$ & $0.00 \%$ & $0.60 \%$ & $0.85 \%$ & $76.86 \%$ & $10.99 \%$ & $2.50 \%$ & $1.14 \%$ \\
$\mu_{b, t}{ }^{E A}$ & $0.00 \%$ & $5.42 \%$ & $4.38 \%$ & $0.00 \%$ & $63.93 \%$ & $5.27 \%$ & $3.38 \%$ \\
$\mu_{s, t}{ }^{E A}$ & $0.44 \%$ & $3.49 \%$ & $0.16 \%$ & $1.60 \%$ & $1.23 \%$ & $45.32 \%$ & $1.88 \%$ \\
$\mu_{e, t}$ & $1.91 \%$ & $23.04 \%$ & $3.47 \%$ & $7.68 \%$ & $8.25 \%$ & $0.14 \%$ & $52.16 \%$ \\
$\mu_{c, t}$ & $2.05 \%$ & $7.05 \%$ & $0.16 \%$ & $0.42 \%$ & $8.99 \%$ & $1.25 \%$ & $3.75 \%$ \\
\hline \hline
\end{tabular}

B. pre-EMU period: $1989-1998$

\begin{tabular}{lrrrrrrr}
\hline \hline & \multicolumn{1}{c}{$r_{t}{ }^{U S}$} & \multicolumn{1}{c}{$b_{t}{ }^{U S}$} & \multicolumn{1}{c}{$s_{t}{ }^{U S}$} & \multicolumn{1}{c}{$r_{t}{ }^{E A}$} & \multicolumn{1}{c}{$b_{t}{ }^{E A}$} & \multicolumn{1}{c}{$s_{t}{ }^{E A}$} & \multicolumn{1}{l}{$e_{t}$} \\
\hline$\mu_{r, t}$ US & $82.89 \%$ & $2.81 \%$ & $0.60 \%$ & $2.82 \%$ & $0.02 \%$ & $0.25 \%$ & $4.95 \%$ \\
$\mu_{b, t}$ US & $9.69 \%$ & $85.26 \%$ & $1.67 \%$ & $1.11 \%$ & $2.54 \%$ & $1.21 \%$ & $0.68 \%$ \\
$\mu_{s, t}$ US & $0.00 \%$ & $4.01 \%$ & $94.39 \%$ & $0.00 \%$ & $1.12 \%$ & $18.74 \%$ & $0.09 \%$ \\
$\mu_{r, t}{ }_{E A}$ & $0.74 \%$ & $0.24 \%$ & $0.27 \%$ & $88.73 \%$ & $0.20 \%$ & $0.00 \%$ & $8.80 \%$ \\
$\mu_{b, t}{ }^{E A}$ & $0.61 \%$ & $6.94 \%$ & $0.30 \%$ & $1.03 \%$ & $81.49 \%$ & $0.01 \%$ & $1.02 \%$ \\
$\mu_{s, t}{ }^{E A}$ & $0.01 \%$ & $0.17 \%$ & $0.00 \%$ & $0.04 \%$ & $2.08 \%$ & $62.76 \%$ & $0.00 \%$ \\
$\mu_{e, t}$ & $3.02 \%$ & $0.02 \%$ & $1.67 \%$ & $5.87 \%$ & $1.44 \%$ & $16.25 \%$ & $84.20 \%$ \\
$\mu_{c, t}$ & $3.03 \%$ & $0.55 \%$ & $1.10 \%$ & $0.39 \%$ & $11.10 \%$ & $0.78 \%$ & $0.25 \%$ \\
\hline \hline
\end{tabular}

C. excluding NBER recession periods

\begin{tabular}{lrrrrrrr}
\hline \hline & \multicolumn{1}{c}{$r_{t}{ }^{U S}$} & \multicolumn{1}{c}{$b_{t}{ }^{U S}$} & \multicolumn{1}{c}{$s_{t}{ }^{U S}$} & \multicolumn{1}{c}{$r_{t}{ }^{E A}$} & \multicolumn{1}{c}{$b_{t}{ }^{E A}$} & \multicolumn{1}{c}{$s_{t}{ }^{E A}$} & \multicolumn{1}{c}{$e_{t}$} \\
\hline$\mu_{r, t}{ }^{U S}$ & $85.32 \%$ & $15.77 \%$ & $0.04 \%$ & $9.18 \%$ & $1.36 \%$ & $0.06 \%$ & $0.37 \%$ \\
$\mu_{b, t}$ US & $6.27 \%$ & $65.61 \%$ & $0.01 \%$ & $1.93 \%$ & $5.05 \%$ & $0.05 \%$ & $0.00 \%$ \\
$\mu_{s, t}$ US & $0.00 \%$ & $0.79 \%$ & $99.39 \%$ & $0.42 \%$ & $0.00 \%$ & $24.21 \%$ & $0.03 \%$ \\
$\mu_{r, t}{ }^{E A}$ & $1.83 \%$ & $0.12 \%$ & $0.10 \%$ & $72.97 \%$ & $0.04 \%$ & $0.00 \%$ & $14.41 \%$ \\
$\mu_{b, t}{ }^{E A}$ & $1.65 \%$ & $9.48 \%$ & $0.02 \%$ & $7.97 \%$ & $92.06 \%$ & $0.12 \%$ & $0.97 \%$ \\
$\mu_{s, t}{ }^{A A}$ & $0.02 \%$ & $0.00 \%$ & $0.00 \%$ & $0.31 \%$ & $0.01 \%$ & $70.15 \%$ & $3.73 \%$ \\
$\mu_{e, t}$ & $0.04 \%$ & $0.93 \%$ & $0.41 \%$ & $7.10 \%$ & $1.27 \%$ & $3.67 \%$ & $80.41 \%$ \\
$\mu_{c, t}$ & $4.86 \%$ & $7.29 \%$ & $0.03 \%$ & $0.12 \%$ & $0.22 \%$ & $1.74 \%$ & $0.08 \%$ \\
\hline \hline
\end{tabular}

Note: the tables report the share of the variance of each series that is explained by the various structural shocks. 
Figure 1: Distribution of structural coefficients of the benchmark model in 500 bootstrap replications

1
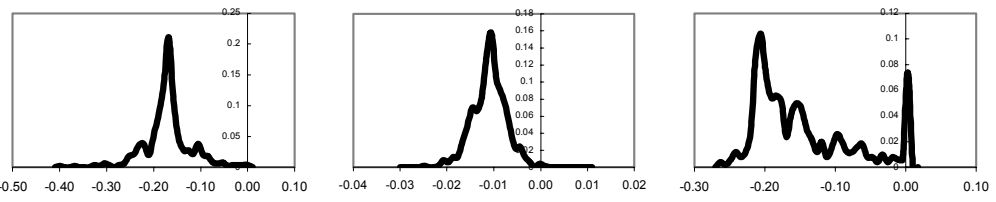

0

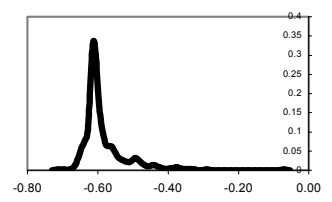

1

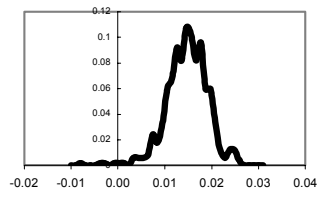

0

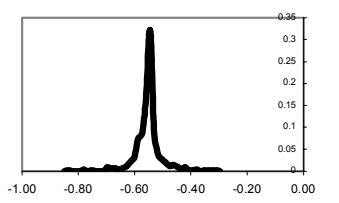

0
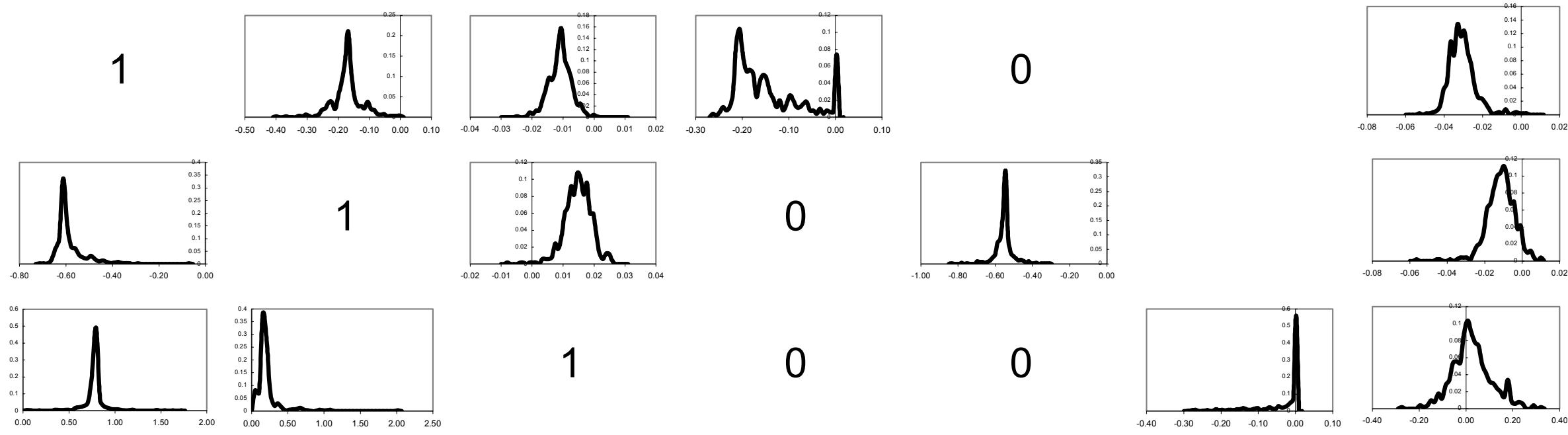

0

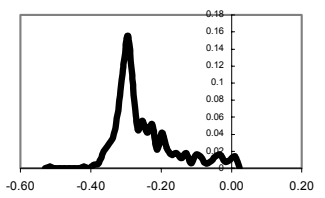

0

0
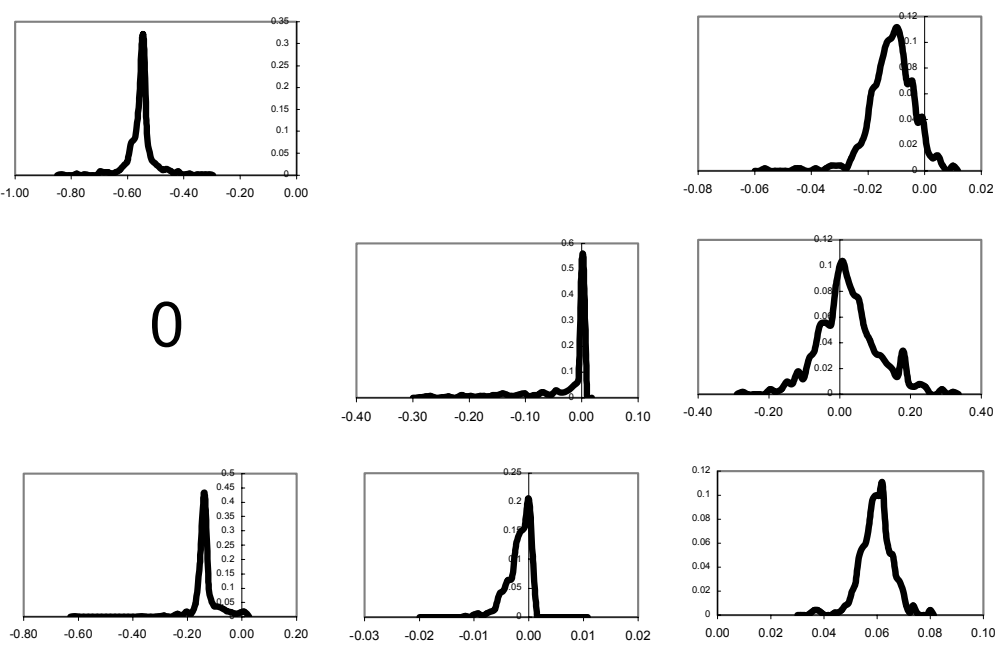

1

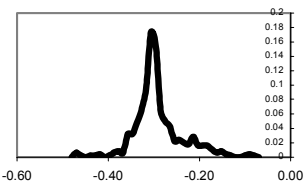

0

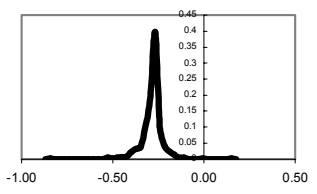

1
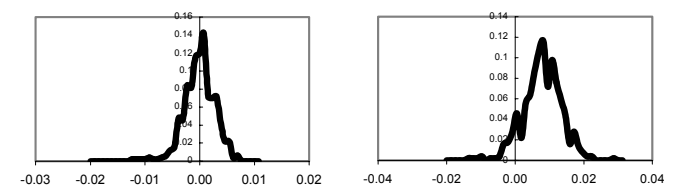

0
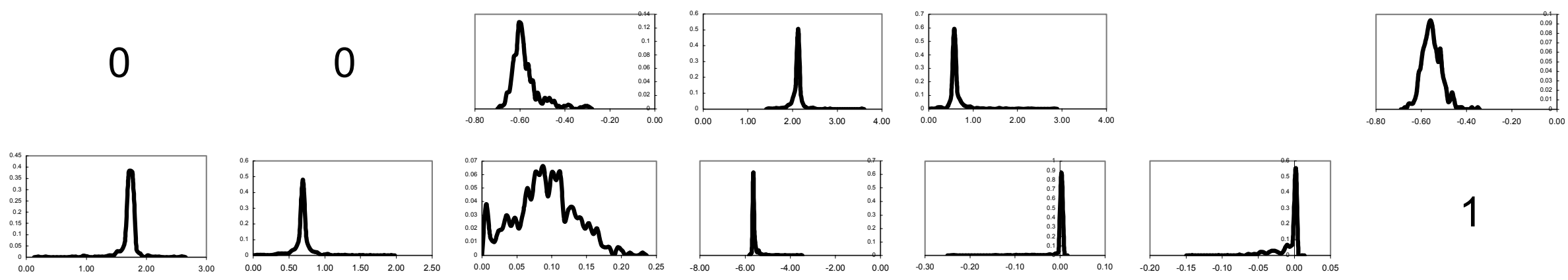
Figure 2: Distribution of reduced-form coefficients of the benchmark model in 500 bootstrap replications
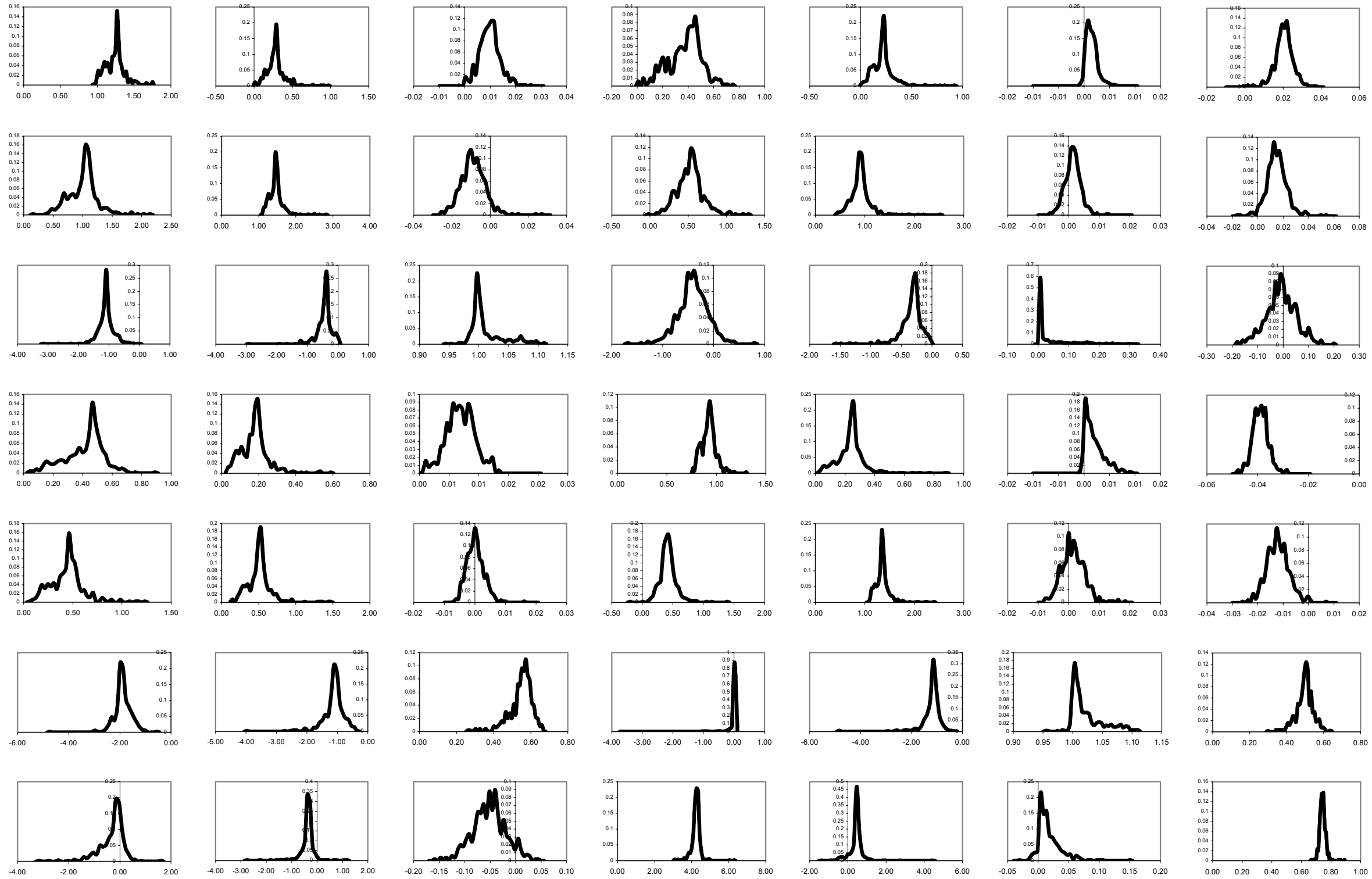